\title{
¿Urban Dry Island Effect Mitigated Urbanization Effect on Observed Warming in China $\mathscr{A}$
}

\author{
JIZENG DU \\ School of Environment, Beijing Normal University, State Key Joint Laboratory of Environmental Simulation and \\ Pollution Control, Beijing, China \\ KAICUN WANG AND SHAOJING JIANG \\ College of Global Change and Earth System Science, Beijing Normal University, Beijing, China \\ BAOSHAN CUI \\ School of Environment, Beijing Normal University, State Key Joint Laboratory of Environmental Simulation and \\ Pollution Control, Beijing, China \\ JIANKAI WANG \\ Chinese Meteorological Administration, Beijing, China \\ CHUANFENG ZHAO AND JiANPING Li \\ College of Global Change and Earth System Science, Beijing Normal University, Beijing, China
}

(Manuscript received 22 October 2018, in final form 2 June 2019)

\begin{abstract}
With urbanization occurring around weather stations, its impact on the observed air temperature has been widely recognized. However, its assessments were varied partially due to the poor understanding of its underlying mechanism. Here, we analyzed the effect of urbanization using observations obtained from $\sim 2200$ weather stations in China from 1960 to 2014. The results showed that the urbanization effect increased from 1960 to 1984 but slowed after 1995 with rapid urbanization in China, particularly in terms of the daily minimum temperature $T_{\min }$ and daily mean air temperature $T_{\text {mean }}$. The urbanization effect is nearly linearly related to the urban-rural contrast of effective cloud cover (including the impact of atmospheric aerosols) derived from the observed sunshine duration. Aerosols increase atmospheric downward longwave radiation $L_{d}$ through their absorption of solar radiation during the daytime, and they trap longwave radiation emitted from the surface during the nighttime. Increased anthropogenic aerosols caused the urban-rural contrast of effective cloud cover to increase from 1960 to 2014. However, the urban-rural contrast of cloud cover remained stable from 1960 to 1984 but substantially decreased due to the "urban dry island effect" after 1995, which compensated for the impact of anthropogenic aerosols on $L_{d}$ and resulted in a stable urbanization effect after 1995. The urban-rural difference in $L_{d}$ increased by $0.57 \mathrm{~W} \mathrm{~m}^{-2}(10 \mathrm{yr})^{-1}$, which resulted in warming of $0.074^{\circ} \mathrm{C}(10 \mathrm{yr})^{-1}(78.2 \%)$ for $T_{\min }, 0.037^{\circ} \mathrm{C}(10 \mathrm{yr})^{-1}(151.5 \%)$ for $T_{\max }$, and $0.056^{\circ} \mathrm{C}(10 \mathrm{yr})^{-1}(96.6 \%)$ for $T_{\text {mean }}$.
\end{abstract}

Denotes content that is immediately available upon publication as open access.

Supplemental information related to this paper is available at the Journals Online website: https://doi.org/10.1175/JCLI-D-180712.s1.

Corresponding author: Kaicun Wang, kcwang@bnu.edu.cn

\section{Introduction}

Cities are the areas that have exhibited the most intense land-cover changes and concentrated energy consumption; therefore, urban climates have some typical characteristics that are not found in background climates, primarily the urban heat island effect (UHI). However, because urban areas account for only $0.5 \%$ of the total global land surface, the contribution of urban 
climate to global or regional climate change is negligible (Schneider et al. 2009). Unfortunately, as major data sources for climate change research, most weather stations tend to be located near urban or suburban regions. With urban extension, the effects of urbanization on nearby stations will become stronger. The enhanced urban heat island effect caused by urbanization will amplify local and regional warming trends estimated from station observations (Fujibe 2011; Karl et al. 1988; Ren et al. 2007). This will introduce uncertainty into the detection of climate change and the evaluation of model simulations. Therefore, it is important to analyze and quantitatively assess the potential effects of urbanization on the large-scale warming trends estimated by station observations (Ren et al. 2015).

Currently, many methods are used to estimate the effects of urbanization on warming trends, such as comparisons between observations and reanalysis products or nearby observations (Cayan and Douglas 1984; Kalnay and Cai 2003). Assessing the urban-rural contrast in warming trends is considered a reliable method that has been widely used to evaluate urbanization effects (Ren et al. 2015). However, in Europe and the United States, studies have suggested that urban and rural areas exhibit obvious differences in their mean temperatures but no significant differences in their warming trends (Gallo et al. 1999; Hansen et al. 2001; Peterson 2003). For example, Gaffin et al. (2008) found that New York City has a clear UHI between $2.0^{\circ}$ and $2.5^{\circ} \mathrm{C}$, but the urban-rural difference in warming trends over the past century has been just $0.03^{\circ} \mathrm{C}(10 \mathrm{yr})^{-1}$. Jones et al. (2008) analyzed the urban-rural differences in London and Vienna and found that the multiyear mean surface air temperatures in urban stations are warmer than those in their rural neighbors by approximately $1.5^{\circ} \mathrm{C}$, whereas there was no significant warming bias between them during 1961-2006. This is because these regions had completed urbanization in the nineteenth century, and they have strong urban heat islands; however, the differences between the warming trends in these urban and rural areas are negligible (Chrysanthou et al. 2014; Jones et al. 1990).

We therefore need to quantify the impact of urbanization process, rather than that of urban status, on the observed warming trends. The process of urbanization in China has become more rapid since the 1980s, with the implementation of the "reform and opening up" policy, and the impact of urbanization on the observed warming has been widely reported (He et al. 2013; Ren et al. 2008; Ren et al. 2015; Wang and Ge 2012; Zhang et al. 2010). However, a diverse array of conclusions has been obtained, and the impact of urbanization on the observed warming in China as estimated from national stations has been determined to vary from close to $0 \%$ to 40\% (Jones et al. 2008; Ren and Zhou 2014).

Jones et al. (2008) estimated urbanization-induced warming trend bias by comparing the data from stations in eastern China with nearby sea surface temperature data and indicated that the contribution of urbanization to warming was approximately $0.1^{\circ} \mathrm{C}(10 \mathrm{yr})^{-1}$ during 1951-2004. Zhou et al. (2004) used reanalysis data (NCEP-R2) as a reference to estimate the effects of urbanization and land-cover change on warming trends in China and suggested that the warming bias attributed to urbanization and land-cover change was approximately $0.05^{\circ} \mathrm{C}(10 \mathrm{yr})^{-1}(11.1 \%)$ from 1979 to 2003 . Ren et al. (2015) compared the annual mean warming trends at national stations with those at nearby rural stations and found a significant contribution of urbanization of $0.074^{\circ} \mathrm{C}(10 \mathrm{yr})^{-1}(24.9 \%)$ to warming over China during 1961-2004. Based on the same datasets and selecting the same reference stations as above, Sun et al. (2016) recently used the optimal fingerprint method to evaluate the urbanization effect on the warming trend over China and attributed approximately $0.094^{\circ} \mathrm{C}(10 \mathrm{yr})^{-1}(34.0 \%)$ of the warming of surface air temperature to urbanization during 1961-2013.

Previous studies have proposed many mechanisms to explain these differences in estimations, such as varying areas and periods, as well as different selecting criteria for rural stations. More mysteriously, the impact of urbanization on the observed air temperature has been stable since 1995, when China began to experience faster urbanization (Sun et al. 2016). Nevertheless, one of the main uncertainties in these estimations arises from a poor understanding of the physical mechanism of how urbanization affects surface air temperatures. The interpretation of the warming effect of urbanization still mainly depends on the principle of urban heat islands, which draws from empirical evidence obtained from a single city during short periods. However, we usually analyze the effect of urbanization on warming trends over periods of decades on a large spatial scale based on many station records, which may yield significantly different results about the physical processes and driving factors of urbanization-induced warming due to the different time scales considered.

The spatial patterns of urban isothermals are similar to a series of concentric circles centered on the urban center, and the surface air temperature decreases from the inside to the outside (McNider et al. 2012; Oke 1982). These isothermals will expand with urbanization so that the surface air temperature of the areas surrounding the urban region will increase. This simple model has been widely used to describe the physical 
process of urbanization affecting the warming trends of stations located near cities, and it has only assessed the direct impact caused by urban heat islands. In addition to air temperature, there are many important climatic factors that will change significantly with urbanization, such as cloud cover, precipitation, and relative humidity. The changes in those key climatic factors would have large effects on the land-atmosphere energy balance and therefore influence local and regional warming. However, in previous studies, those effects were usually ignored in analyses of the characteristics of urbanization effects on warming trends.

However, the substantial impacts of changes in climatic factors on urbanization-induced warming have been generally valued by related researches. K. Wang et al. (2017) found that the urban heat island effect on air temperatures is stronger on cloudy days than on clear days, which indicated that changes in cloud cover may have a significant effect on urban warming by increasing downward longwave radiation at night. Cao et al. (2016) attributed the diurnal contrast in urban warming to the increasing hazes that compensate for the urban warming in daily maximum temperature $T_{\max }$ by reducing the surface solar radiation and enhance the urban warming of daily minimum temperature $T_{\min }$ by increasing the downward longwave radiation. Additionally, the expansion of impervious surfaces with urbanization amplifies urban warming by reducing evapotranspiration and increasing the proportion of sensible heat flux in the total net radiation absorbed by the land surface (Kato and Yamaguchi 2007; Zhou et al. 2011), whereas urbanization in the desert may exhibit the opposite effect on warming due to the oasis effect (Boudjellal and Bourbia 2018; Kai et al. 1997). Therefore, to better understand the physical mechanism of urban warming, it is crucial to analyze the changes in key climatic factors under urbanization and explore their corresponding relationships with temperature changes based on the land-atmosphere energy balance.

Surface solar radiation $R_{s}$ and downward longwave radiation $L_{d}$ are the most important components of land-atmosphere energy balance (Iacono et al. 2008; Stephens and Greenwald 1991), and they have significant effects on the long-term trends of air temperatures on various spatial scales (Du et al. 2018; Wild 2016). Additionally, they are sensitive to changes in climatic factors that are vulnerable to urbanization (Inoue and Kimura 2004; Romanov 1999; Unkašević et al. 2001; Y. Wang et al. 2017). In this paper, we used the urbanrural contrast to estimate the impact of urbanization on the warming trends of $T_{\max }, T_{\min }$, and $T_{\text {mean }}$. We found that the declining trend of urban clouds caused by the urban dry island effect is an important reason for the slowdown of the urbanization effect on warming over China after 1995.

\section{Data and methods}

\section{a. Data and statistical methods}

We used the observations of daily surface air temperature (including $T_{\max }, T_{\min }$, and $T_{\text {mean }}$ ) and other variables to calculate $R_{s}$ and $L_{d}$ (e.g., cloud cover and water vapor) from approximately 2400 meteorological stations in the Chinese network during 1960-2014, which were collected and processed by the China Meteorological Administration (CMA). This dataset comprises 2243 stations with more than 40 years of available observations of the required variables from 1960 to 2014 (see Fig. 1a). The records in this dataset have been checked using strict quality control measures, such as the identification of outliers, assessment of spatiotemporal consistency, and correction of suspicious and erroneous data. All observed records from weather stations were homogenized using the RHtestsV4 software package provided by Wang et al. (2010), and a detailed description of the homogenization procedure was given by Xu et al. (2013).

To evaluate the urbanization warming effect, the method depends on how urban versus rural stations are identified and whether their climate records are homogeneous. Two main approaches have been used to classify a station as urban or rural: those based on indices (e.g., population, urban built-up areas, night lights, and NDVI) (Gallo et al. 1999; Owen 1998; Portman 1993) or geostatistical analyses (e.g., EOF decomposition, cluster analysis, and urban isothermals) (Ren et al. 2015; J. Wang et al. 2012). However, those methods are unable to reflect the urbanization process and are sensitive to the density of stations (J. Wang et al. 2017). Ren et al. (2010) used a comprehensive procedure to identify rural stations from all meteorological stations based on metadata and station history information. The criteria used in this procedure include the distance of a station from its nearest city, as well as its times of station relocations, percentage of surrounding built-up areas, and length of valid records, as described in detail by Ren et al. (2015). Finally, a total of 143 stations met the criteria and were classified as rural stations (Ren et al. 2015). To reduce the effect of inhomogeneous records, we removed rural stations with nonclimatic shifts and 132 rural stations were reserved; other stations were classified as urban stations (see Fig. 1a).

Contrasting Figs. 1c and 1d, the number of urban stations is much larger than that of rural stations in valid grids especially in East China. Owing to the rapid urban 

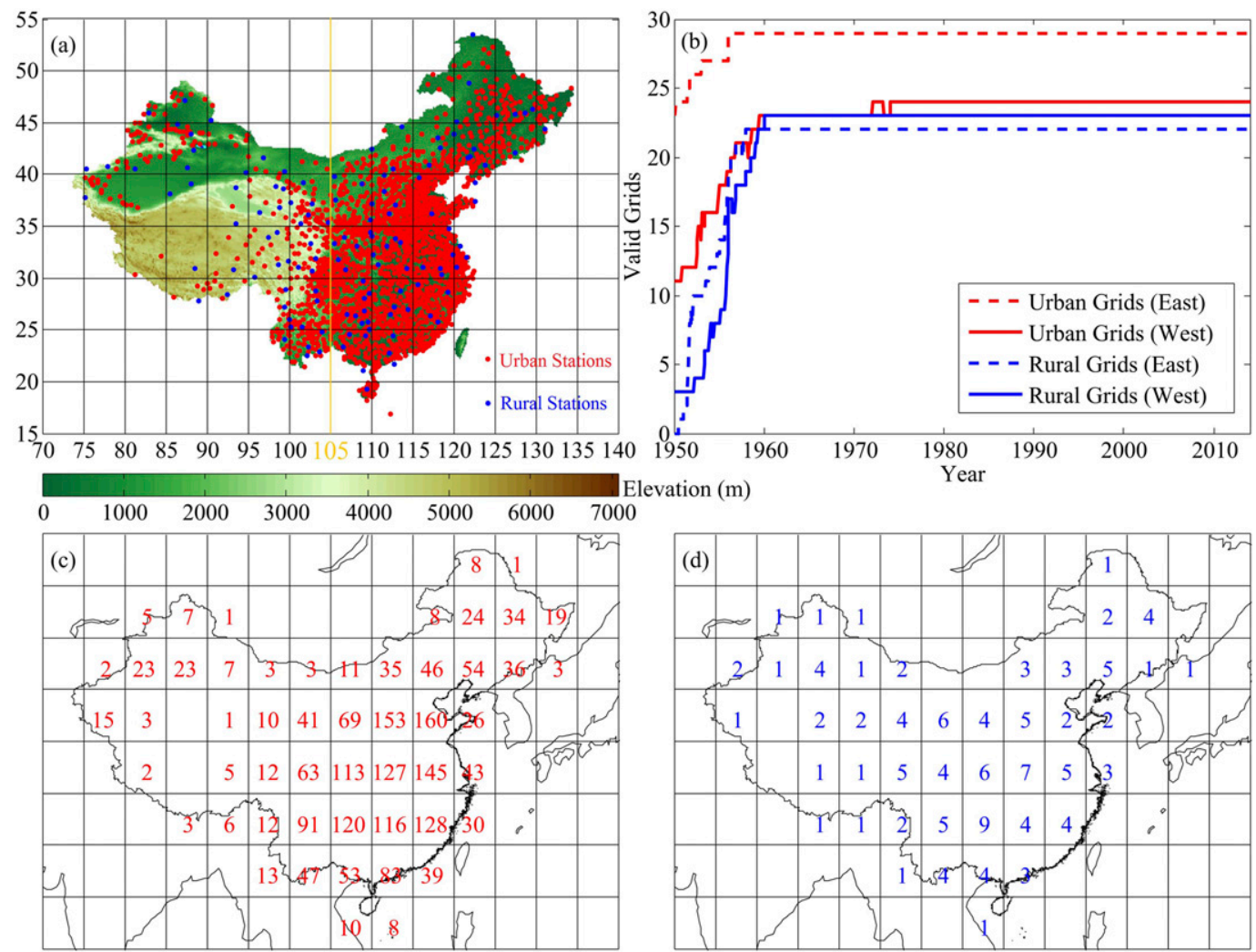

FIG. 1. (a) Spatial distribution of selected weather stations over mainland China; blue spots denote rural stations, and red spots denote urban stations. (b) The changes in urban and rural valid grids over time in East China and West China. (c) The number of urban stations in valid grids. (d) The number of rural stations in valid grids.

expansion and most stations located nearby urban areas, there are fewer and fewer stations in China that are completely free of the effect of urbanization (see Fig. S1 in the online supplemental material). To minimize the effect of urbanization, we adopted a set of strict criteria to select rural stations as reference, namely that all stations that may be affected by urbanization are classified as urban stations (Ren et al. 2010; Ren et al. 2015). Consequently, there are fewer stations classified as rural stations, which may bring sampling errors. Using a bootstrap procedure involving the resampling of the urban-rural difference series, Sun et al. (2016) evaluated the sampling errors for this urban-rural classification and indicated that the urbanization-induced signals were robust against the sampling errors. Note that all results were applied to regional averages rather than a single station.

In this paper, all statistical analyses were based on monthly anomalies derived from daily observations. The value of a month was not used when it had more than seven missing days, and the period of 1971-2000 was used as the reference period to calculate anomalies. As shown in Fig. 1a, the density of stations over China is extremely uneven: dense in eastern China but sparse in western China. To reduce the impact of this spatial heterogeneity, we averaged the anomalies obtained from the stations into $5^{\circ} \times 5^{\circ}$ grid cells. The grid size is a compromise between the spatial coverage and resolution of valid grids, which include both urban stations and rural stations. Additionally, we divided China into western and eastern regions along the $105^{\circ} \mathrm{E}$ line based on their differences in socioeconomic development and background climate. All regional averages were calculated using the area-weighted average of the available gridded values in each region.

Additionally, the Pearson's correlation coefficients were calculated, using the detrended anomaly series of the variables that removed the impact of trends, to evaluate the linear relationship between the variables. The long-term trends of variables were calculated by the linear regression based on the ordinary least squares method. The confidence level of the correlation coefficients and long-term trends were tested by the Student's $t$ test, and the $95 \%$ confidence intervals were provided for trends. All trend estimations and attribution analyses were performed in valid grids. The 
differences in time series between the urban and rural stations were attributed to the urbanization effect.

\section{b. Estimation of cloud cover and atmospheric aerosol loading}

Cloud cover is a routine observation collected at weather stations over China. The cloud amount is observed by professional observers and recorded in tenths (e.g., clear sky is recorded as $0 / 10$ and an overcast sky is recorded as 10/10). The locations used for observations should be able to see as much of the entire sky as possible. When the sky is partially obscured by obstacles (e.g., mountains, buildings), the cloud cover should be estimated from the unobscured portion of the sky. If some of the sky is covered by precipitation, this part of the sky should be seen as being covered by clouds that produce precipitation. Cloud cover is observed at 6-h intervals at 0200, 0800, 1400, and 2000 BST (Beijing standard time), and the daily mean cloud cover represents the average of these four observations. An additional observation was conducted near each evening to evaluate the general features and evolution trends of clouds to prepare for observing cloud cover at night. Previous studies have suggested that long records of visual observations from weather stations could be used to analyze the interannual variabilities and secular trends of cloud cover (Eastman and Warren 2013; Norris and Wild 2009; Warren et al. 2007).

In addition to clouds, aerosols are an important impact factor that affects the land-atmosphere radiation energy balance by decreasing $R_{s}$ and increasing $L_{d}$. In terms of $R_{s}$, it is clear that the reflection, absorption, and scattering caused by aerosols can lead to a decrease in the $R_{s}$ absorbed by the land surface (Schwartz 1996). In terms of $L_{d}$, aerosols can absorb and reemit longwave radiation from the land surface and therefore reduce the longwave cooling efficiency, which is similar to the radiative forcing caused by greenhouse gases (Cao et al. 2016; Dufresne et al. 2002; Panicker et al. 2008). Additionally, the dramatic increase in aerosol emissions is a typical phenomenon of urbanization. However, there are no available long records of the atmospheric loading of aerosols, which limits the attribution of changes in climate to changes in aerosols. Here, we used an index derived from sunshine duration to represent the changes in radiative forcing due to both cloud cover and aerosols, which is named the effective cloud cover (CA):

$$
\mathrm{CA}=1-\left[k_{0}+k_{1}(n / N)+k_{2}(n / N)^{2}\right],
$$

where $k_{0}, k_{1}$, and $k_{2}$ are the regression coefficients derived from the observed $R_{s}$ and the observed sunshine duration $n$ in different regions (He et al. 2018); $n / N$ is the ratio of the observed sunshine duration to the clear-sky sunshine duration $N$, which depends on changes in both clouds and aerosols (Wang 2014). Furthermore, we estimated the radiative effects of aerosols based on the differences between those derived from observed cloud cover $(\mathrm{CF})$ and those derived from CA.

\section{c. Calculation of $R_{s}$ and $L_{d}$}

The term $R_{s}$ is the main resource of land surface energy and the driving force of the seasonal and diurnal cycles of air temperature. However, observation stations of $R_{s}$, with a total amount of less than 120 , are very sparse and much lower than the number of observation stations for other variables. Additionally, the sensitivity drift of observation instruments caused the observed $R_{s}$ to decrease faster after 1990 than it did beforehand, and instrument replacements led to a false jump in observed records from 1990 to 1993 (He et al. 2018; Wang et al. 2015). Yang et al. (2006) proposed an efficient hybrid model with which to calculate $R_{s}$ using the sunshine duration:

$$
R_{s}=(1-f) R_{c},
$$

where $R_{c}$ is the theoretical maximum solar radiation reaching the land surface under clear skies, which is derived from the ozone thickness, turbidity coefficients, and auxiliary meteorological variables (e.g., relative humidity and barometric pressure); $f$ is the observed fraction of cloud cover (CF) or the index derived from sunshine duration (CA). The CF-derived $R_{S}$ data reflect the impact of clouds on $R_{s}$, and the CA-derived $R_{s}$ data reflect the impact of both clouds and aerosols on $R_{s}$ (Magee et al. 2014; Y. Wang et al. 2012). Hence, the difference between these values can be used to evaluate the impact of changes in aerosols on $R_{s}$, which is also applicable to $L_{d}$.

Surface downward longwave radiation $L_{d}$ is another important component in land surface energy balance, especially at night; however, observations of this quantity are extremely sparse and most observed records are short. To compensate for the lack of observations, many efficient empirical models have been proposed to derive the surface downward longwave radiation under clearsky conditions $L_{\mathrm{dc}}$ based on air temperature and vapor pressure (see Table 1). Previous studies have indicated that the performances of these models primarily vary with background geography and climate. For instance, Wang and Liang (2009) compared the estimates obtained from the models of Brunt (1932) and Brutsaert (1975) with observations of $L_{d}$ and suggested that the former was better in sites where the elevation is less than $1000 \mathrm{~m}$, while the latter was better in sites located at 
TABLE 1. Empirical methods used to estimate surface downward longwave radiation under clear-sky conditions $L_{\mathrm{dc}}$. Note that $E_{a}$ is the water vapor pressure ( $\mathrm{hPa}) ; T_{a}$ is the near-surface air temperature $(\mathrm{K}) ; \sigma$ is the Stefan-Boltzmann constant $(5.67 \times$ $\left.10^{-8} \mathrm{~W} \mathrm{~m}^{-2} \mathrm{~K}^{-4}\right)$; and $\varepsilon_{a}$ is the atmospheric emissivity of longwave radiation.

\begin{tabular}{ll}
\hline \hline \multicolumn{1}{c}{ Source } & \multicolumn{1}{c}{ Model } \\
\hline Ångström (1915) & $L_{\mathrm{dc}}=\varepsilon_{a} \sigma T_{a}^{4}$ \\
Angström (1924) & $\varepsilon_{a}=0.83-0.18 \times 10^{-0.067 E_{a}}$ \\
Brunt (1932) & $\varepsilon_{a}=0.605+0.048 E_{a}^{0.5}$ \\
Idso and Jackson $(1969)$ & $\varepsilon_{a}=0.7+5.95 \times 10^{-5} E_{a} \exp \left(1500 / T_{a}\right)$ \\
Brutsaert (1975) & $\varepsilon_{a}=1.24+\left(E_{a} / T_{a}\right)^{1 / 7}$ \\
Prata (1996) & $\varepsilon_{a}=1-(1+w) \exp \left[-(1.2+3 w)^{0.5}\right]$ \\
& $w=46.5 E_{a} / T_{a}$ \\
\hline
\end{tabular}

higher elevations. Because no empirical model is superior to all others in all regions, we selected five widely used empirical models that were combined for the calculation of $L_{\mathrm{dc}}$ to improve the accuracy of the results and facilitate the evaluation of their uncertainty (Wang and Dickinson 2013).

Clouds can absorb longwave radiation and reemit a portion back to the land surface; therefore, cloud cover has a strong effect on the surface downward longwave radiation. Crawford and Duchon (1999) proposed a version of the equation used to quantify the effects of clouds on $L_{d}$ :

$$
L_{d}=L_{\mathrm{dc}}\left(1-f^{\mu}\right)+v f^{\mu} \sigma T_{a}^{4},
$$

where $L_{\mathrm{dc}}$ is the surface downward longwave radiation under clear-sky conditions, $T_{a}$ is the surface air temperature, and $\sigma$ is the Stefan-Boltzmann constant $\left(5.67 \times 10^{-8} \mathrm{~W} \mathrm{~m}^{-2} \mathrm{~K}^{-4}\right)$. Also, $\mu$ and $v$ are empirical coefficients, and many studies have proven that the retrieved $L_{d}$ values agree best with observations when they are set as 1 (Choi et al. 2008; Duarte et al. 2006; Kjaersgaard et al. 2007). The values of $f$ are the same as those in Eq. (2), which were calculated using CF or CA; the comparison between them is used to evaluate the impacts of clouds and aerosols, respectively, on $L_{d}$.

It is essential to verify the reliability of models, because both $R_{s}$ and $L_{d}$ were derived by empirical models rather than observation. For $R_{s}$, many existing studies have proved that the sunshine duration-derived $R_{s}$ agreed well with observation in interannual variability, and even better in long-term homogeneity in China (He et al. 2018; Tang et al. 2011; Wang et al. 2015). Because of the technical challenge and high cost, $L_{d}$ is not observed operationally for long time periods and is just observed in the short term by, for example, the Baseline Surface Radiation Network (BSRN), which leads to few studies on the validation of derived $L_{d}$ especially in China (Bilbao and de Miguel 2007; Ma et al. 2014; Wang and Liang 2009). Therefore, using multiple popular empirical models to derive $L_{d}$ is a compromise method to identify the uncertainty of derived $L_{d}$ and improve the confidence of our conclusion.

\section{d. The attribution of the urbanization effect to radiative forcing}

The relationships between climate variables and $R_{s}$ $\left(L_{d}\right)$ involve many complex physics processes, and most of them are nonlinear. Therefore, it is difficult to use simple regression analysis to quantify the impacts of climatic factors on $R_{s}$ and $L_{d}$. In this paper, based on the empirical models mentioned above, we calculated $R_{s}$ and $L_{d}$ using the daily observation and climatology values (i.e., the monthly average during 1970-2010), respectively, of climate factors. The difference between the $R_{s}\left(L_{d}\right)$ values calculated based on observations and climatology values is used to quantify the respective effects and interaction effects of climate variables on $R_{s}\left(L_{d}\right)$.

Similar to the sketch in Fig. S2a, all of these variables have effects on $R_{s}\left(L_{d}\right)$ and there are significant interactions between them. To better evaluate those effects, we established a series of combinations of input variables based on the observation and climatology, and then the equation set is constructed according to the difference of $R_{s}\left(L_{d}\right)$ obtained by various combinations of input variables (see Fig. S2c). By solving the equation set, we can determinate every section of effects shown in Fig. S2a, thus the individual effect of each variable, the interaction effects among them, and their total effects on $R_{s}\left(L_{d}\right)$ can be quantified (see Fig. S2b).

Furthermore, the impacts of $R_{s}$ and $L_{d}$ on surface air temperature are estimated using a linear regression model, and they can be expressed as

$$
T=S_{R_{s}} R_{s}+S_{L_{d}} L_{d}+c+\varepsilon,
$$

where $T, R_{s}$, and $L_{d}$ denote the time series of the monthly anomalies of surface air temperatures $\left(T_{\min }\right.$, $T_{\text {max }}$, and $\left.T_{\text {mean }}\right)$, surface solar radiation, and surface downward longwave radiation, respectively. Also, $S_{R_{s}}$ and $S_{L_{d}}$ are regression coefficients that denote the sensitivity of temperatures to the forcing from $R_{s}$ and $L_{d} ; c$ is a constant, and $\varepsilon$ represents the residuals. The goodness of fit of the regression $R^{2}$ and residual consistency are estimated to test the confidence in quantifying the effect of $R_{s}$ and $L_{d}$ on urban-rural warming difference; $R^{2}$ is calculated in every station to explore the magnitude and spatial pattern of the effect of surface radiation fluxes on near-surface air temperatures. To verify whether the probability distribution of the regression residuals is normal, the residual consistency is evaluated by Kolmogorov-Smirnov test at a grid scale. 
TABLE 2 . The trends ( $\pm 95 \%$ confidence interval) of the national average and urban-rural differences before and after adjustment for $T_{\max }, T_{\min }$, and $T_{\text {mean }}$ during $1960-2014$ [ ${ }^{\circ} \mathrm{C}(10 \mathrm{yr})^{-1}$ ].The effects of $R_{s}$ and $L_{d}$ on temperatures are adjusted by Eq. (5). All trends are evaluated by area-weighted average based on the grids. The boldface font denotes the trend is significant at $95 \%$ confidence level.

\begin{tabular}{cccrr}
\hline \hline Trend & Variables & East China & West China & China \\
\hline National average & $T_{\text {max }}$ & $\mathbf{0 . 1 9 2} \pm \mathbf{0 . 0 5 2}$ & $\mathbf{0 . 2 4 2} \pm \mathbf{0 . 0 4 3}$ & $\mathbf{0 . 2 1 6} \pm \mathbf{0 . 0 4 3}$ \\
& $T_{\text {min }}$ & $\mathbf{0 . 3 3 7} \pm \mathbf{0 . 0 4 4}$ & $\mathbf{0 . 3 7 8} \pm \mathbf{0 . 0 3 4}$ & $\mathbf{0 . 3 5 7} \pm \mathbf{0 . 0 3 5}$ \\
& $T_{\text {mean }}$ & $\mathbf{0 . 2 4 3} \pm \mathbf{0 . 0 4 5}$ & $\mathbf{0 . 2 7 6} \pm \mathbf{0 . 0 3 6}$ & $\mathbf{0 . 2 5 9} \pm \mathbf{0 . 0 3 7}$ \\
Raw (urban-rural) & $T_{\text {max }}$ & $0.004 \pm 0.005$ & $\mathbf{0 . 0 4 6} \pm \mathbf{0 . 0 1 1}$ & $\mathbf{0 . 0 2 5} \pm \mathbf{0 . 0 0 6}$ \\
& $T_{\text {min }}$ & $\mathbf{0 . 1 0 6} \pm \mathbf{0 . 0 0 5}$ & $\mathbf{0 . 0 8 4} \pm \mathbf{0 . 0 1 1}$ & $\mathbf{0 . 0 9 5} \pm \mathbf{0 . 0 0 6}$ \\
& $T_{\text {mean }}$ & $\mathbf{0 . 0 6 2} \pm \mathbf{0 . 0 0 4}$ & $\mathbf{0 . 0 5 4} \pm \mathbf{0 . 0 1 0}$ & $\mathbf{0 . 0 5 8} \pm \mathbf{0 . 0 0 6}$ \\
Adjusted (urban-rural) & $T_{\text {max }}$ & $-\mathbf{0 . 0 3 0} \pm \mathbf{0 . 0 0 5}$ & $0.006 \pm 0.008$ & $\mathbf{0 . 0 1 3} \pm \mathbf{0 . 0 0 5}$ \\
& $T_{\text {min }}$ & $\mathbf{0 . 0 3 9} \pm \mathbf{0 . 0 0 4}$ & $0.001 \pm 0.006$ & $\mathbf{0 . 0 2 1} \pm \mathbf{0 . 0 0 4}$ \\
& $T_{\text {mean }}$ & $\mathbf{0 . 0 1 0} \pm \mathbf{0 . 0 0 3}$ & $0.003 \pm 0.005$ & $\mathbf{0 . 0 0 4} \pm \mathbf{0 . 0 0 3}$ \\
& & & &
\end{tabular}

To intuitively display of the role of $R_{s}$ and $L_{d}$, we adjust their effects on temperatures based on the regression analysis above. The approach for the adjustment was shown as

$$
T_{\text {adjust }}=T_{\text {raw }}-S_{R_{s}} R_{s}-S_{L_{d}} L_{d},
$$

where $T_{\text {raw }}$ and $T_{\text {adjust }}$ denote the monthly anomalies of temperatures before and after adjustment respectively; $S_{R_{s}}, S_{L_{d}}, R_{s}$, and $L_{d}$ are the same as those in Eq. (5). We used $T_{\text {raw }}$ and $T_{\text {adjust }}$ to calculate the interannual variability and long-term trend of urban-rural differences, respectively. By comparison, we can see how much of the urbanization-induced warming was achieved by the changes in $R_{s}$ and $L_{d}$.

\section{Results}

\section{a. The urban-rural differences in changes in temperature}

Based on the urban-rural differences in warming trends, we can estimate the effect of urbanization on the warming rate of surface air temperature from 1960 to 2014. As shown in Table 2, on national average, the urban-rural difference of $T_{\text {mean }}$ increased by $0.058^{\circ} \pm$ $0.006^{\circ} \mathrm{C}(10 \mathrm{yr})^{-1}(22.3 \%$ of its overall warming, $\pm 95 \%$ confidence interval) during 1960-2014, which is similar to those obtained in previous studies $\left[0.047^{\circ}-0.074^{\circ} \mathrm{C}\right.$ $\left.(10 \mathrm{yr})^{-1}, 20.6 \%-27.3 \%\right]$ based on urban-rural comparisons (Ren and Zhou 2014; Ren et al. 2015; Ren and Ren 2011; Zhang et al. 2010). The urban-rural difference of $T_{\min }$ and $T_{\max }$ increased by $0.095^{\circ} \pm 0.006^{\circ} \mathrm{C}$ $(10 \mathrm{yr})^{-1}$ and $0.025^{\circ} \pm 0.006^{\circ} \mathrm{C}(10 \mathrm{yr})^{-1}$, respectively, corresponding to $26.7 \%$ and $11.4 \%$ of their overall warming, respectively. The increase of urban-rural difference is faster for $T_{\min }$ than it is for $T_{\max }$, which is consistent with previous studies (Ren and Zhou 2014; Zhou et al. 2004).
As shown in Fig. 2, the increase of urban-rural difference for $T_{\text {mean }}$ was faster in East China than that in West China, with rates of $0.062^{\circ} \pm 0.004^{\circ} \mathrm{C}(10 \mathrm{yr})^{-1}$ and $0.054^{\circ} \pm 0.010^{\circ} \mathrm{C}(10 \mathrm{yr})^{-1}$, respectively; these differences corresponded well to the observed regional differences in urban development. As shown in Table 2 and Fig. S5, the urban warming of $T_{\min }$ was also higher in East China $\left[0.106^{\circ} \pm 0.005^{\circ} \mathrm{C}(10 \mathrm{yr})^{-1}\right]$ than that in West China $\left[0.084^{\circ} \pm 0.011^{\circ} \mathrm{C}(10 \mathrm{yr})^{-1}\right]$, while the urban warming of $T_{\max }$ in East China was negligible $\left[0.004^{\circ} \pm\right.$ $0.005^{\circ} \mathrm{C}(10 \mathrm{yr})^{-1}$ ] and much lower than that in West

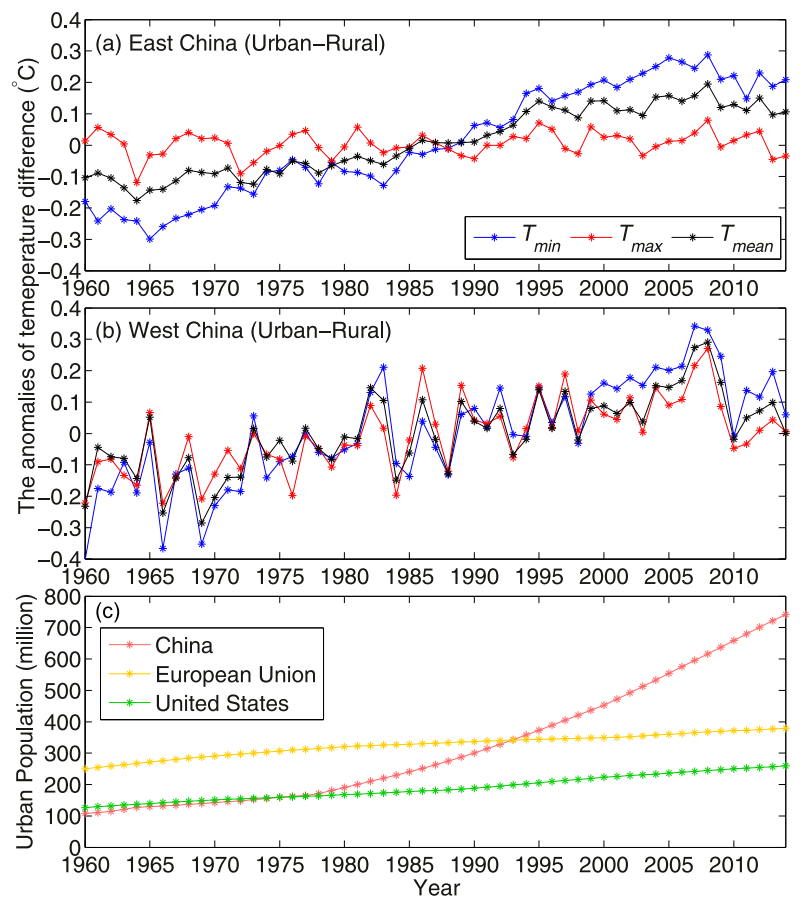

FIG. 2. Annual anomalies of urban-rural differences in $T_{\min }$, $T_{\text {max }}$, and $T_{\text {mean }}$ from 1960-2014 in (a) East China and (b) West China. (c) The annual changes in the urban populations of China, Europe, and the United States. Five-year moving-average curves for (a) and (b) are shown in Fig. S10. 
China $\left[0.046^{\circ} \pm 0.011^{\circ} \mathrm{C}(10 \mathrm{yr})^{-1}\right]$. The east-west differences in urbanization effects indicate that the estimated urbanization-induced warming based on data from the eastern region would be larger than those obtained using the national average data or data from other regions (Ren et al. 2008; Yang et al. 2011; Zhang et al. 2010).

Importantly, although urbanization over China was accelerating according to urban population data (Fig. 2c), urban warming began to slow down after 1995 in East China (Fig. 2a). A recent study by Sun et al. (2016) found that the signal pattern of the effects of urbanization on temperatures showed a similar feature, namely that urban warming over China has risen rapidly since the 1980s but tended to stabilize after the mid1990s, but they did not propose a reason or underlying mechanism for this phenomenon.

\section{b. Changes in variables and their radiative forcing under urbanization}

In addition to the feedback of warming, the radiative energy balance between the atmosphere and the land surface is sensitive to changes in clouds, aerosols, and atmospheric humidity. Therefore, we evaluated the interannual variabilities and long-term trends of the urban-rural differences in related climate variables over China based on observations during 1960-2014.

First, a contrastive analysis was conducted for the changes in the difference of cloud cover and sunshine duration between urban and rural area. For interannual variability, there are no significant relationship between their urban-rural differences (see Fig. S3); For longterm trend, both of them were in decreasing trend during 1960-2014, especially over East China. The results indicate that the changes in the urban-rural difference for cloud cover is not sufficient to explain the decreasing trend of that for sunshine duration (see Fig. S4), which is consistent with existing studies (Sanchez-Lorenzo et al. 2009; Wang et al. 2013; Zheng et al. 2008). The main reason for those inconsistencies is the effect of aerosols loading, which can absorb and scatter the solar radiation (Sanchez-Romero et al. 2014; K. Wang et al. 2012; Y. Wang et al. 2012). Therefore, we calculated the effective cloud cover $f$ by the sunshine duration and cloud cover respectively. The differences between sunshine duration-derived $f(\mathrm{CA})$ and cover-cover-derived $f(\mathrm{CF})$ are considered as the effect of aerosol loading.

The CA is calculated using Eq. (1), which can capture the exact variabilities in both cloud cover and aerosol concentrations (Ma et al. 2015; K. Wang et al. 2012). With urbanization, the urban-rural difference of CA increased by $0.382 \% \pm 0.030 \%(10 \mathrm{yr})^{-1}$, while that of $\mathrm{CF}$ decreased slightly by $-0.120 \% \pm 0.036 \%(10 \mathrm{yr})^{-1}$

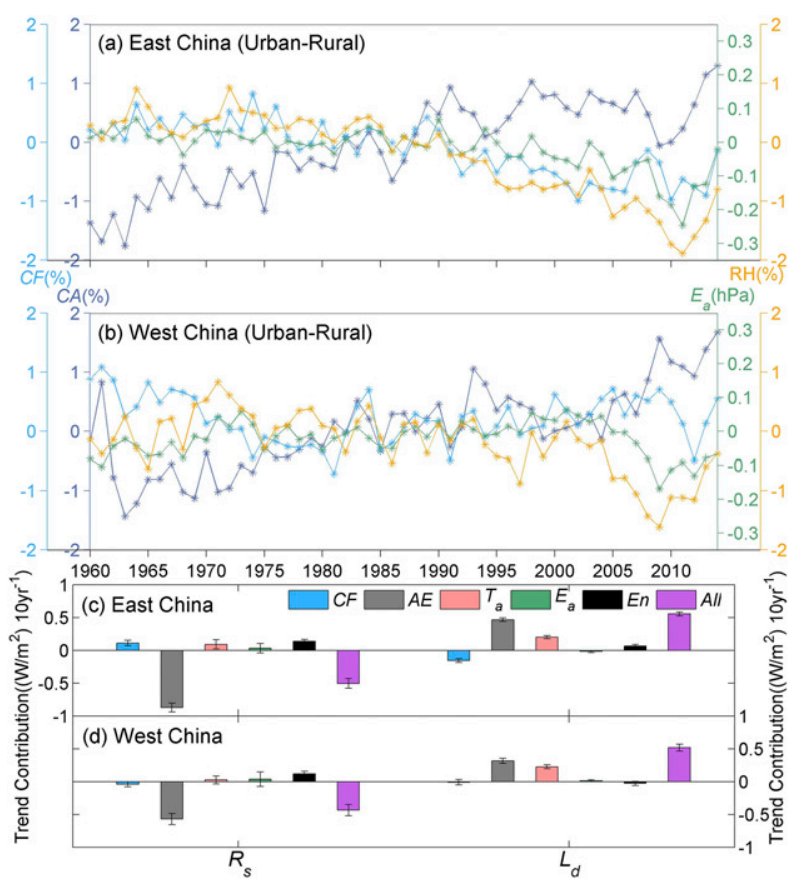

FIG. 3. (top) Annual anomalies of cloud fraction (CF), cloud and aerosols (CA), relative humidity ( $\mathrm{RH})$, and water vapor pressure $E_{a}$ for (a) East China and (b) West China, and (bottom) their contributions to the urbanization-induced changes in $R_{s}$ and $L_{d}$ in (c) East China and (d) West China. " $E_{n}$ " and "All" denote the interaction effect and total effect of variables on the trend of $R_{s}$ and $L_{d}$, and the attrition approach is shown in Fig. S2. Note that the effect of aerosols (AE) is estimated as the difference between those of CF and CA. Five-year moving-average curves for (a) and (b) are shown in Fig. S11.

from 1960 to 2014. This result implies that the increasing trend of CA was mainly caused by the enhancement of aerosol emissions with urbanization over China. The relative humidity (RH) decreased by $-0.294 \% \pm$ $0.025 \%(10 \mathrm{yr})^{-1}$ with urbanization, which is consistent with the urban dry island effect reported by previous studies (Ackerman 1987; Lokoshchenko 2017; Moriwaki et al. 2013; Yang et al. 2017). Although the air temperature increased, the urban dry island introduced a decreasing trend $\left[-0.014 \pm 0.003 \mathrm{hPa}(10 \mathrm{yr})^{-1}\right]$ of water vapor pressure $E_{a}$ (Hao et al. 2018; Henry et al. 1985).

As shown in Fig. 3 and Fig. S6, the urban-rural difference of CA increased faster in East China $[0.413 \% \pm$ $\left.0.036 \%(10 \mathrm{yr})^{-1}\right]$ than that in West China $[0.353 \% \pm$ $\left.0.045 \%(10 \mathrm{yr})^{-1}\right]$, whereas the decreasing rate of $\mathrm{CF}$ caused by urbanization was faster in East China $\left[-0.222 \% \pm 0.033 \%(10 \mathrm{yr})^{-1}\right]$ than that in West China $\left[-0.021 \% \pm 0.043 \%(10 \mathrm{yr})^{-1}\right]$. This result indicated that the increasing trend of urban aerosols in East China was much faster than that in West China. The decreasing trends of relative humidity caused by urbanization were 

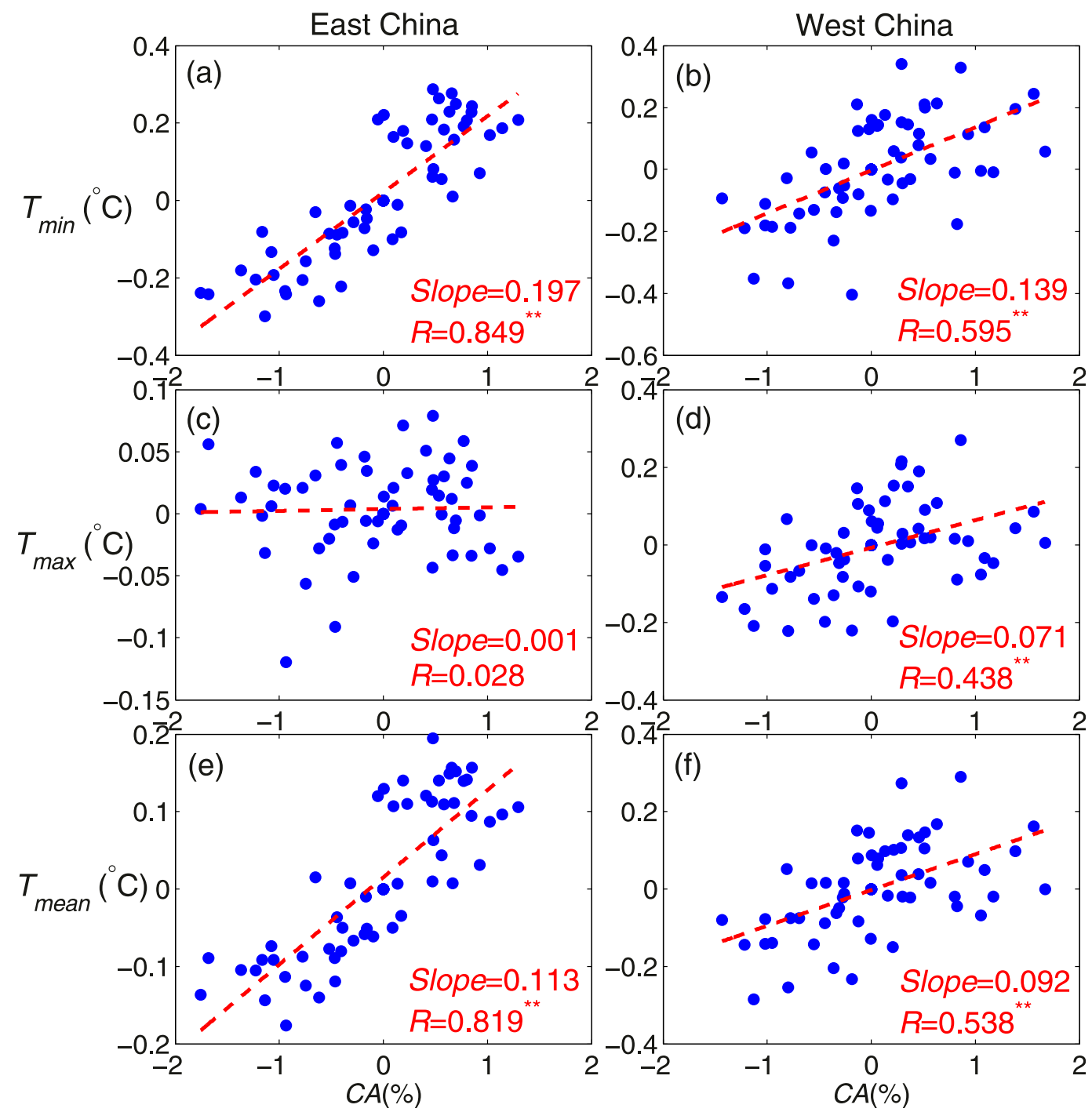

FIG. 4. Scatterplots between clouds and aerosols (CA) and temperatures [(a),(b) daily minimum temperatures $T_{\min }$; (c),(d) daily maximum temperatures $T_{\max }$; and (e),(f) daily mean temperatures $\left.T_{\text {mean }}\right]$ based on detrended annual anomalies in (left) East China and (right) West China. The slope is the linear regression of the coefficients of temperatures for $\mathrm{CA}$, and $R$ values are the correlation coefficients. The superscript of $R$ denotes the confidence level: Two asterisks (**) indicate that the correlation is significant at the $99 \%$ confidence level; one asterisk $(*)$ indicates that the correlation is significant at the $95 \%$ confidence level; otherwise, the correlation is insignificant.

$0.384 \% \pm 0.027 \%(10 \mathrm{yr})^{-1}[-0.027 \pm 0.004 \mathrm{hPa}$ $\left.(10 \mathrm{yr})^{-1}\right]$ in East China and $0.199 \% \pm 0.027 \%(10 \mathrm{yr})^{-1}$ $\left[-0.001 \pm 0.004 \mathrm{hPa}(10 \mathrm{yr})^{-1}\right]$ in West China, which indicated that the urban drying rate in the former was almost twice that in the latter.

Importantly, the contrast between Figs. 2 and 3 reveals that there is good consistency between CA and $T_{\min }$ in the urbanization-induced trend, which both exhibited increasing trends until 1995 and then became stable in East China while maintained a slower increasing trend in West China from 1960 to 2014. As shown in Fig. 4, there were significant correlations between $\mathrm{CA}$ and temperature in the interannual variabilities of urban-rural differences. Notably, $T_{\min }$ exhibited the most significant correlation with CA, followed by $T_{\text {mean }}$, while the correlation between $T_{\max }$ and CA was the lowest and insignificant in East China. In addition to $T_{\max }$, the correlations and sensitivities of temperatures to CA were higher in East China than in West China. These results indicated that CA may be a key factor controlling the interannual variability and long-term trends of the urbanization effects on observed temperatures. Hence, it is critical to explore how urbanization-induced changes in CA affect the radiative 
TABLE 3. The trends ( $\pm 95 \%$ confidence level) of national area-weighted average and urban-rural difference of cloud fraction $(\mathrm{CF})$, surface air temperature $T_{a}$, water vapor pressure $E_{a}$, and surface downward longwave radiation $L_{d}$ during 1960-2014. Note that the boldface font denotes the trend is significant at $95 \%$ confidence level.

\begin{tabular}{|c|c|c|c|c|}
\hline Trend & Variables & East China & West China & China \\
\hline National average & $\begin{array}{l}\mathrm{CF}\left[\%(10 \mathrm{yr})^{-1}\right] \\
\mathrm{CA}\left[\%(10 \mathrm{yr})^{-1}\right] \\
E_{a}\left[\mathrm{hPa}(10 \mathrm{yr})^{-1}\right] \\
\mathrm{RH}\left[\%(10 \mathrm{yr})^{-1}\right] \\
R_{s}\left[\mathrm{~W} \mathrm{~m}{ }^{-2}(10 \mathrm{yr})^{-1}\right] \\
L_{d}\left[\mathrm{~W} \mathrm{~m}^{-2}(10 \mathrm{yr})^{-1}\right]\end{array}$ & $\begin{array}{r}-0.139 \pm 0.226 \\
\mathbf{1 . 0 1 3} \pm \mathbf{0 . 1 9 2} \\
0.034 \pm 0.034 \\
-\mathbf{0 . 5 0 3} \pm \mathbf{0 . 1 2 2} \\
\mathbf{- 1 . 6 6 3} \pm \mathbf{0 . 3 6 5} \\
\mathbf{1 . 8 5 6} \pm \mathbf{0 . 1 9 3}\end{array}$ & $\begin{aligned}-0.339 & \pm 0.177 \\
0.206 & \pm 0.125 \\
0.083 & \pm 0.017 \\
-0.077 & \pm 0.112 \\
-0.401 & \pm 0.249 \\
1.501 & \pm 0.270\end{aligned}$ & $\begin{aligned}-\mathbf{0 . 2 3 5} & \pm \mathbf{0 . 1 7 5} \\
\mathbf{0 . 6 2 9} & \pm \mathbf{0 . 1 3 9} \\
\mathbf{0 . 0 5 7} & \pm \mathbf{0 . 0 2 3} \\
-\mathbf{0 . 2 9 9} & \pm \mathbf{0 . 0 9 7} \\
-\mathbf{1 . 0 6 3} & \pm \mathbf{0 . 2 5 7} \\
\mathbf{1 . 6 8 8} & \pm \mathbf{0 . 2 0 4}\end{aligned}$ \\
\hline Urban-rural & $\begin{array}{l}\mathrm{CF}\left[\%(10 \mathrm{yr})^{-1}\right] \\
\mathrm{CA}\left[\%(10 \mathrm{yr})^{-1}\right] \\
E_{a}\left[\mathrm{hPa}(10 \mathrm{yr})^{-1}\right] \\
\mathrm{RH}\left[\%(10 \mathrm{yr})^{-1}\right] \\
R_{s}\left[\mathrm{~W} \mathrm{~m}{ }^{-2}(10 \mathrm{yr})^{-1}\right] \\
L_{d}\left[\mathrm{~W} \mathrm{~m}^{-2}(10 \mathrm{yr})^{-1}\right]\end{array}$ & $\begin{aligned}-0.222 & \pm 0.033 \\
\mathbf{0 . 4 1 3} & \pm \mathbf{0 . 0 3 6} \\
-0.027 & \pm 0.004 \\
\mathbf{0 . 3 8 4} & \pm \mathbf{0 . 0 2 7} \\
-\mathbf{0 . 5 0 5} & \pm \mathbf{0 . 0 7 3} \\
\mathbf{0 . 5 5 4} & \pm \mathbf{0 . 0 3 2}\end{aligned}$ & $\begin{aligned}-0.021 & \pm 0.043 \\
\mathbf{0 . 3 5 3} & \pm \mathbf{0 . 0 4 5} \\
\mathbf{- 0 . 0 0 1} & \pm \mathbf{0 . 0 0 4} \\
\mathbf{0 . 1 9 9} & \pm \mathbf{0 . 0 3 9} \\
\mathbf{- 0 . 4 3 5} & \pm \mathbf{0 . 0 8 8} \\
\mathbf{0 . 5 1 5} & \pm \mathbf{0 . 0 5 3}\end{aligned}$ & $\begin{aligned}-\mathbf{0 . 1 2 4} & \pm \mathbf{0 . 0 2 8} \\
\mathbf{0 . 3 8 2} & \pm \mathbf{0 . 0 3 0} \\
-\mathbf{0 . 0 1 4} & \pm \mathbf{0 . 0 0 3} \\
\mathbf{0 . 2 9 3} & \pm \mathbf{0 . 0 2 5} \\
-\mathbf{0 . 4 7 1} & \pm \mathbf{0 . 0 5 5} \\
\mathbf{0 . 5 3 6} & \pm \mathbf{0 . 0 3 1}\end{aligned}$ \\
\hline
\end{tabular}

energy balance and the underlying mechanism of the correlation between CA and air temperatures.

As shown in Figs. $3 \mathrm{c}$ and $3 \mathrm{~d}$, of the three driving factors of $R_{s}$, the contribution of aerosols (AE) is the largest, as it resulted in $R_{s}$ decreasing by $-0.724 \pm$ $0.055 \mathrm{~W} \mathrm{~m}^{-2}(10 \mathrm{yr})^{-1}$ (74.1\% of overall effects). The changes in other variables are positively correlated with $R_{s}$, but their impact on $R_{s}$ is negligible [0.032$\left.0.059 \mathrm{~W} \mathrm{~m}^{-2}(10 \mathrm{yr})^{-1}\right]$, and all of their contributions account for only $12.7 \%$ of the overall effects. In terms of $L_{d}$, AE was also the driving factor for urban-rural differences and increased $L_{d}$ by $0.391 \pm 0.024 \mathrm{~W} \mathrm{~m}^{-2}$ $(10 \mathrm{yr})^{-1}(54.9 \%)$, followed by the feedback of $T_{a}$ $\left[0.211 \pm 0.021 \mathrm{~W} \mathrm{~m}^{-2}(10 \mathrm{yr})^{-1} ; 29.5 \%\right]$ and cloud cover $\left[-0.085 \pm 0.025 \mathrm{~W} \mathrm{~m}^{-2}(10 \mathrm{yr})^{-1} ; 11.9 \%\right]$; the direct contribution of $E_{a}$ is negligible $\left[-0.003 \pm 0.010 \mathrm{~W} \mathrm{~m}^{-2}\right.$ $\left.(10 \mathrm{yr})^{-1} ; 0.4 \%\right]$.

Additionally, the increasing greenhouse gases would also increase $L_{d}$, which may result in climate warming on a global scale without spatial difference but has little effect on the regional difference of radiative fluxes at a grid scale (Wang and Liang 2009). Therefore, the changes of radiative fluxes caused by greenhouse gases cannot make much difference to our results.

\section{c. Changes in $R_{s}$ and $L_{d}$ and their contributions to urban warming}

As shown in Table 3, the urban-rural difference of $R_{s}$ decreased by $-0.471 \pm 0.055 \mathrm{~W} \mathrm{~m}^{-2}(10 \mathrm{yr})^{-1}$, accounting for $44.3 \%$ of the overall decreasing trend of $R_{s}$ in China from 1960 to 2014. The urban-rural difference of $L_{d}$ increased by $0.536 \pm 0.071 \mathrm{~W} \mathrm{~m}^{-2}(10 \mathrm{yr})^{-1}$, accounting for $31.7 \%$ of the overall increasing trend of $L_{d}$ during this period. The urbanization-induced decreases (increases) of $R_{s}\left(L_{d}\right)$ were slightly higher in East China than in West China by $16.1 \%(7.6 \%)$.
As shown in Figs. S7 and S8, there were significant correlations between $R_{s}\left(L_{d}\right)$ and surface air temperatures. The national average of correlation coefficients between temperatures and $R_{s}\left(L_{d}\right)$ ranged from 0.71 $(0.77)$ to $0.86(0.93)$, and all grids were significant at the $95 \%$ confidence level, without significant urban-rural or east-west differences. Afterward, the regression analysis was used to quantify the effect of $R_{s}$ and $L_{d}$ on temperatures [see Eq. (2)]. As shown in Fig. 5, the areaweighted national mean of $R^{2}$ for regression models are $0.80,0.65$, and 0.72 for $T_{\min }, T_{\max }$, and $T_{\text {mean }}$, respectively. This result indicates that the most of variabilities in temperatures can be explained by $R_{s}$ and $L_{d}$. The urban-rural difference of residuals derived from regression models followed normal distribution at $95 \%$ confidence level in same grid (Figs. 5g-i). Therefore, the urban-rural differences in warming were mainly caused by the urban-rural difference in $R_{s}$ and $L_{d}$.

The national mean sensitivity of $T_{\max }$ to $R_{s}$ was $0.107^{\circ} \pm$ $0.025^{\circ} \mathrm{CW}^{-1} \mathrm{~m}^{-2}$ and was much larger than that of $T_{\min }$ $\left(0.053^{\circ} \pm 0.018^{\circ} \mathrm{CW}^{-1} \mathrm{~m}^{-2}\right)$, which was consistent with the fact that changes in $R_{s}$ mainly affect temperatures during the daytime. However, the effects of $L_{d}$ on temperatures have no significant diurnal contrast; therefore, the national mean sensitivity of $T_{\max }$ to $L_{d}$ was $0.174^{\circ} \pm 0.035^{\circ} \mathrm{CW}^{-1} \mathrm{~m}^{-2}$ and was similar to that of $T_{\min }\left(0.184^{\circ} \pm 0.025^{\circ} \mathrm{CW}^{-1} \mathrm{~m}^{-2}\right)$, which were consistent with those calculated in previous studies (Cao et al. 2016; Markowicz et al. 2003; Panicker et al. 2008). The sensitivity values of $T_{\text {mean }}$ to $R_{s}\left(L_{d}\right)$, between those of $T_{\max }$ and $T_{\min }$, were $0.081^{\circ} \pm 0.023^{\circ} \mathrm{CW}^{-1} \mathrm{~m}^{-2}$ and $0.179^{\circ} \pm 0.029^{\circ} \mathrm{CW}^{-1} \mathrm{~m}^{-2}$ respectively. The sensitivity of temperatures to $R_{s}$ and $L_{d}$ exhibited no significant urban-rural differences. However, all sensitivities are larger in West China than in East China (see Figs. S7 and S8), which is consistent with the fact that East China is 

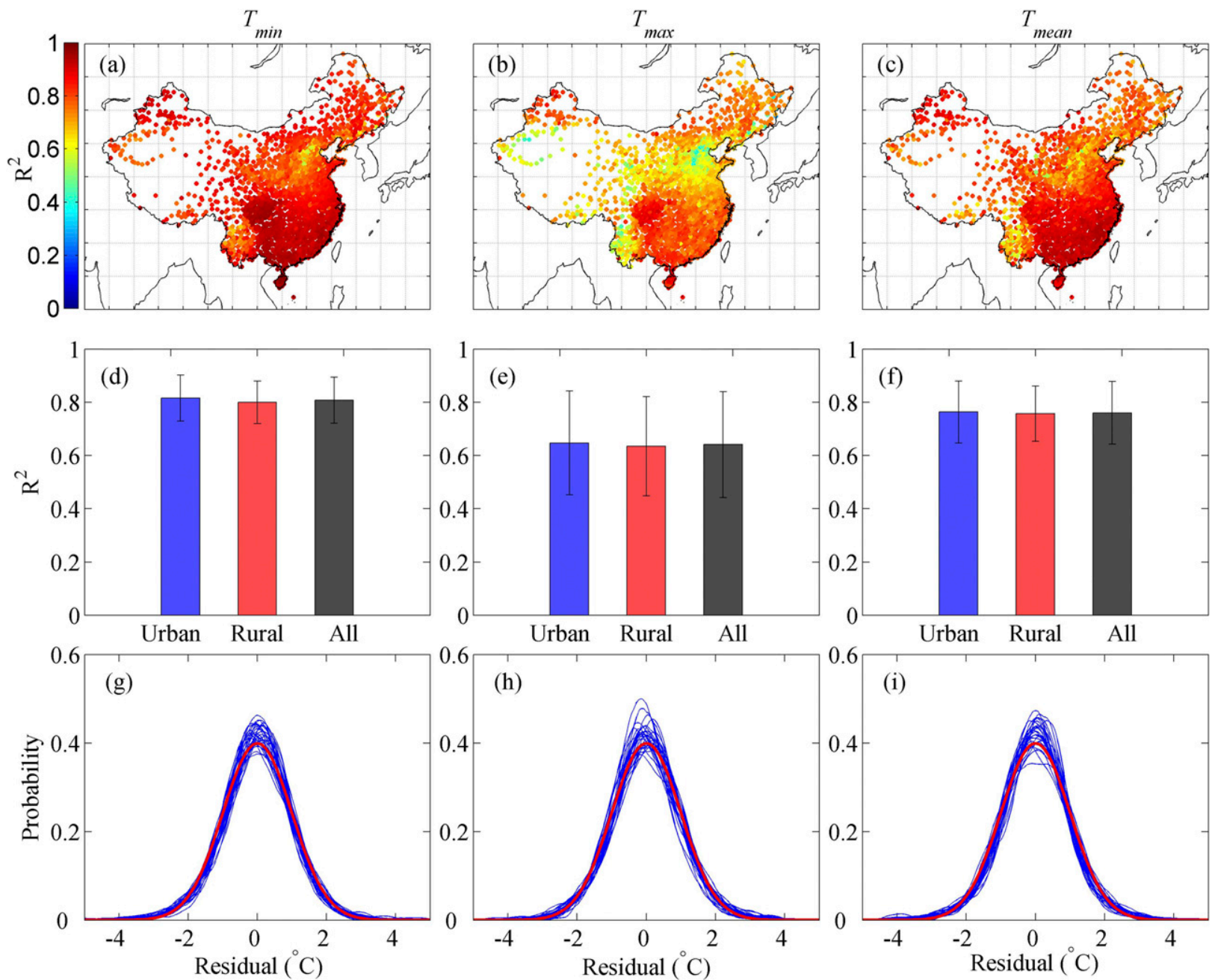

FIG. 5. (a)-(c) Spatial pattern and (d)-(f) regional average of goodness of fit $R^{2}$ of linear regression of temperatures to surface solar radiation $R_{s}$ and downward longwave radiation $L_{d} \cdot(\mathrm{g})-(\mathrm{h})$ The probability distribution of the urban-rural difference for regression residuals. The blue lines represent curves for the probability distribution of the regression residuals in every grid. The red line represents the curve of standard normal distribution. By contrast, the probability distributions of the regression residuals are similar to the standard normal distribution, and all of them passed the $95 \%$ confidence test.

wetter than West China. Compared with the western arid regions, the eastern humid regions have more surface absorbed energy that has turned into latent heat flux and therefore decreased the sensitivities of temperatures to $R_{s}$ and $L_{d}$.

Based on the sensitivities calculated in the last section, we evaluated the contributions of $R_{s}$ and $L_{d}$ to the urban warming of temperatures. As shown in Fig. 6, the increase of urban-rural difference in $L_{d}$ was the main radiative forcing for the urban-rural difference in warming, which increased $T_{\min }, T_{\max }$, and $T_{\text {mean }}$ by $0.102^{\circ} \pm 0.011^{\circ} \mathrm{C}$ $(10 \mathrm{yr})^{-1}, 0.082^{\circ} \pm 0.013^{\circ} \mathrm{C}(10 \mathrm{yr})^{-1}$, and $0.093^{\circ} \pm$ $0.011^{\circ} \mathrm{C}(10 \mathrm{yr})^{-1}$, respectively, from 1960 to 2014 . The effect of urbanization on $R_{s}$ decreased $T_{\max }, T_{\min }$, and $T_{\text {mean }}$ by $-0.044^{\circ} \pm 0.014^{\circ} \mathrm{C}(10 \mathrm{yr})^{-1},-0.026^{\circ} \pm 0.012^{\circ} \mathrm{C}$
$(10 \mathrm{yr})^{-1}$, and $-0.037^{\circ} \pm 0.012^{\circ} \mathrm{C}(10 \mathrm{yr})^{-1}$, respectively, which offset some of the urbanization-induced warming caused by $L_{d}$.

Hence, the overall effects of urbanization-induced radiative forcing increased $T_{\min }, T_{\max }$, and $T_{\text {mean }}$ by $0.074^{\circ} \pm 0.009^{\circ} \mathrm{C}(10 \mathrm{yr})^{-1}, 0.037^{\circ} \pm 0.011^{\circ} \mathrm{C}(10 \mathrm{yr})^{-1}$, and $0.056^{\circ} \pm 0.009^{\circ} \mathrm{C}(10 \mathrm{yr})^{-1}$, respectively. Although the urbanization-induced radiative forcing was stronger in East China, the sensitivities of temperatures to $R_{s}$ and $L_{d}$ were higher in West China (see Figs. S2 and S3); thus, the urban warming attributed to urbanization-induced radiation forcing was slightly higher in West China than in East China. Because the warming effect of $L_{d}$ is stronger on $T_{\min }$ than $T_{\max }$ and the cooling effect of $R_{s}$ is stronger on $T_{\max }$ than $T_{\min }$, the radiative forcing caused 


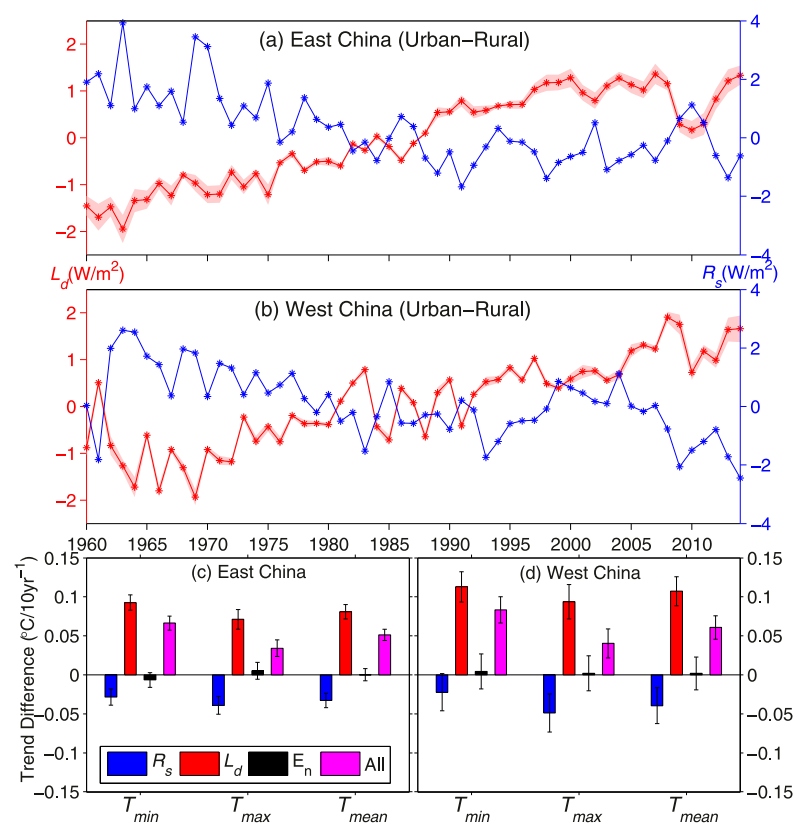

FIG. 6. Interannual changes in downward longwave radiation $L_{d}$ (red lines) and surface solar radiation $R_{s}$; (blue lines) in (a) East China and (b) West China. (c),(d) Contributions of $L_{d}, R_{s}$, their interaction effects $E_{n}$, and the total effects (All) to the warming trends of temperatures in (c) East China and (d) West China. Note that the shading around the red lines in (a) and (b) indicates the spread of the $L_{d}$ values derived from the five empirical models. Five-year moving-average curves for (a) and (b) are shown in Fig. S12.

by urbanization contributed a stronger warming effect to $T_{\min }$ than $T_{\max }$, which explained $58.5 \%$ of the diurnal contrast in urban warming.

\section{d. The contrast in urban warming before and after adjusting radiative forcing}

Based on the results presented above, we adjusted the impacts of $R_{s}$ and $L_{d}$ on temperatures; to better understand the impacts of $R_{s}$ and $L_{d}$ on the temporal and spatial patterns of urbanization effects, we compared the urban warming results obtained before and after this adjustment.

The interannual variabilities of urban-rural difference in temperatures were stronger before 2000 than that after 2000 in West China (see Fig. 2b). As shown in Fig. S1a, the number of stations had no obvious change in 2000 in West China. As shown in Fig. 7, after adjustment, the interannual variability of urban-rural difference in temperatures degrades significantly, especially in West China. The standard deviation of the detrended yearly series decreased by $53.7 \%, 40.3 \%$, and $69.5 \%$ for $T_{\min }, T_{\max }$, and $T_{\text {mean }}$, respectively, in West China during 1960 to 2014 (Fig. 7b). The changes of interannual variability in East China are relatively

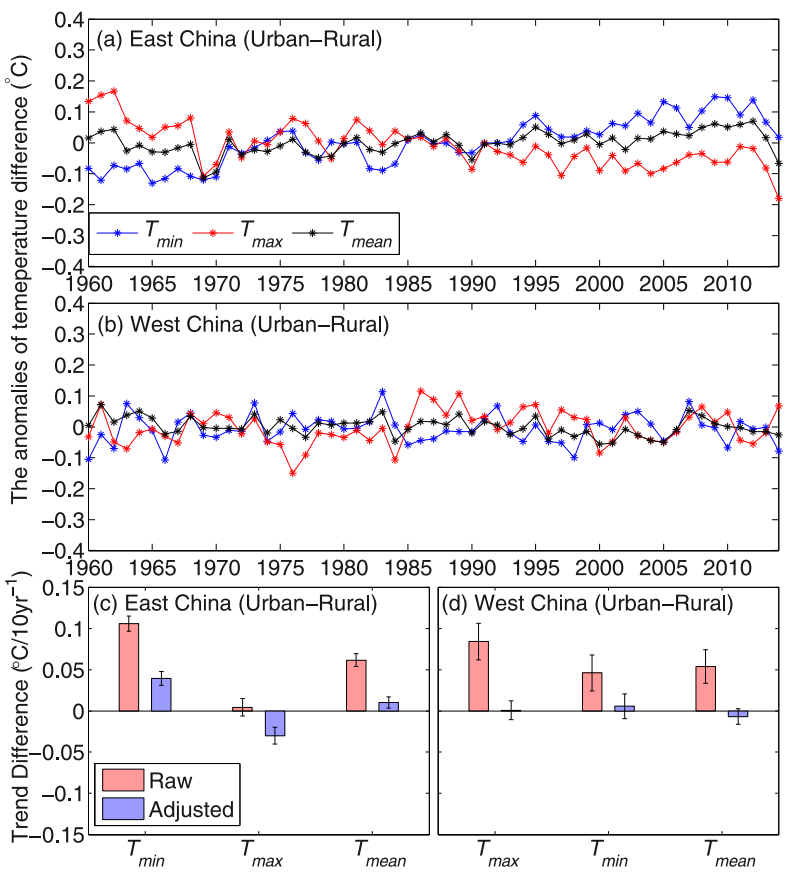

FIG. 7. Five-year moving-average curves of the urban-rural differences in $T_{\max }, T_{\min }$, and $T_{\text {mean }}$ after adjusting for the effects of $R_{s}$ and $L_{d}$ in (a) East China and (b) West China. (c),(d) Urban-rural differences in the warming rates for $T_{\max }, T_{\min }$, and $T_{\text {mean }}$ before and after adjusting the effects of $R_{s}$ and $L_{d}$. Five-year movingaverage curves for (a) and (b) are shown in Fig. S13.

smaller, and the standard deviation of detrended yearly series decreased by $20.8 \%$ and $5.2 \%$ for $T_{\min }$ and $T_{\text {mean }}$, respectively, but increased by $27.0 \%$ for $T_{\max }$ (Fig. 7a). Additionally, the difference of interannual variability before and after 2000 has almost disappeared, which indicates that $R_{s}$ and $L_{d}$ play an important role in the change of interannual variability of urban-rural difference for temperatures in West China.

For long-term trend, after adjustment, the urban warming of $T_{\text {mean }}$ decreased from $0.058^{\circ} \mathrm{C}(10 \mathrm{yr})^{-1}$ to $0.002^{\circ} \mathrm{C}(10 \mathrm{yr})^{-1}$, accounting for $96.6 \%$ of the overall urban warming in East China (see Table 2 and Figs. S9g-i). Without the effect of radiative forcing caused by urbanization, the warming rate of $T_{\max }$ was lower in urban areas than that in surrounding rural areas by $-0.030^{\circ} \mathrm{C}$ $(10 \mathrm{yr})^{-1}$, but the urban warming trend of $T_{\min }$ was still higher than that in rural areas by $0.039^{\circ} \mathrm{C}(10 \mathrm{yr})^{-1}$ (see Fig. 7c and Figs. S9a-c). In West China, after this adjustment, the urban warming of temperatures decreased by $87.6 \%-99.0 \%$ and almost disappeared (see Fig. $7 \mathrm{~d}$ and Figs. S9d-f), which indicates that the urban warming in West China is mainly attributed to the radiative forcing caused by urbanization.

Based on the periodic feature of urban-rural difference in warming, the study period is divided into three segments including 1960-80, 1981-95, and 1996-2014. 
As shown in Fig. 8, during 1960-80, the urban-rural difference in temperature increased gradually, without exhibiting a significant east-west difference. After 1980, the urban warming in East China sped up, while that in West China gradually slowed down (see Table S1). However, the urban warming of $T_{\min }$ and $T_{\text {mean }}$ has fallen sharply and tend to disappear after 1995. Detailed descriptions of the trends in every segment are shown in Table S1.

As mentioned above, urban warming showed two significant turning points in 1980 and 1995. Therefore, we compared the differences in the trends of the urbanization warming effects during three periods (1960-80, 1981-95, and 1996-2014) before and after this adjustment. As shown in Table S1, after the adjustment, the urban-rural difference in warming for $T_{\text {mean }}$ between $1960-80$ and $1981-95$ decreased by $62.3 \%$ in East China and $75.5 \%$ for $T_{\text {mean }}$ in West China, which is mainly attributed to the decrease in the difference of the urban warming of $T_{\min }$ between those two periods. The turning point in 1995 mainly occurred in East China, and the difference between the urban warming of $T_{\text {mean }}$ in 1981-95 and 1996-2014 decreased by $98.1 \%$ after adjustment (see Fig. 8 and Table S1).

\section{Discussion}

Over the past decades, China has experienced the fastest urbanization over the world, and the urban percentage increased from $19.8 \%$ in 1960 to $54.8 \%$ in 2014 (see Fig. 2c). The urban expansion has a significant effect on weather stations and thus adds a spurious trend to the observed records. In this paper, we intended to explore the underlying mechanism of the urbanization effect on warming in order to estimate the warming trend over China more accurately.

During 1960-2014, the urban-rural difference in temperatures increased significantly over China, in good agreement with the rapid urbanization in this period. As shown in Fig. 2, the variability of urbanization-caused warming could be roughly divided in three stages. In the first stage (1960-80), the urban-rural difference in temperatures showed an increasing trend especially in $T_{\min }$ (see Fig. 8a), which indicated that the urbanization has a significant effect on local warming. Owing to the "Down to the Countryside Movement" and the lack of statistical capacity (Xie et al. 2008), urban population reflected that urbanization over China was in hiatus or even retrogression (Fig. 2c). However, the production of steel, coal, oil, and electricity increased by $33 \%, 91.7 \%$, $449 \%$, and $146 \%$ respectively during this period (China State Statistical Bureau 1994), indicating that China has undergone rapid urbanization.
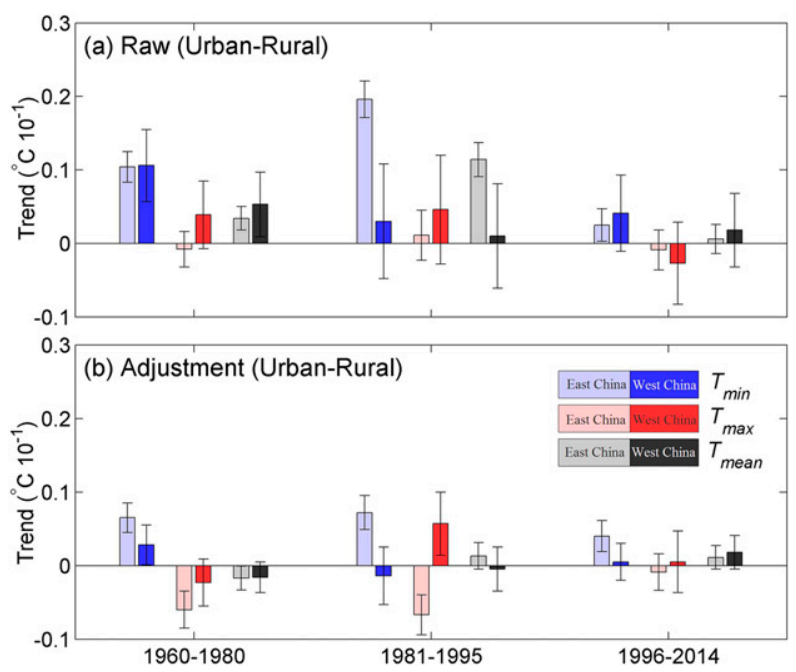

FIG. 8. Urban-induced warming for daily minimum temperature $T_{\min }$, daily maximum temperature $T_{\max }$, and daily mean temperature $T_{\text {mean }}$ during 1960-80, 1981-95, and 1996-2014. (a) Urban-induced trend for temperatures during those periods of raw dataset. (b) Urban-induced trend for temperatures during those periods after adjusting the effects of $R_{s}$ and $L_{d}$.

In second stage (1981-95), China gradually transformed from a planned economy to a market economy and began to launch the reform and opening-up policy. With more harbors and labor, East China had an advantage in developing the industry and foreign trade over West China. Consequently, the urbanization sped up in the former but slowed down in the latter, which explains how the urbanization-induced warming increased in East China while decreasing in West China as well as the similar trend pattern for CA (see Figs. 2 and 8).

However, after 1995, the urban-rural difference of temperatures trended to a hiatus even though urbanization was accelerating in East China (see Fig. 2a). On the contrary, with the implementation of the strategy of developing underdeveloped western provinces, the urbanization accelerated and amplified the urbanizationinduced warming in West China after 1995 (see Fig. 2b). Therefore, in the third stage (1995-2014), the urbanization-induced warming in West China surpassed that in East China (see Fig. 8a). In general, the interdecadal variabilities of urban-rural difference in temperatures agreed well with the process of urbanization in China, apart from the hiatus of urbanization-caused warming after 1995 .

To investigate the hiatus of urbanization-induced warming after 1995, we analyzed the key factors for the land-atmosphere interaction, including cloud cover, aerosols, and air humidity. As shown in Fig. 3a, before 1995, the urban-rural difference for CF and $E_{a}$ had no significant trend while that for CA rose with increasing 
aerosol emissions in East China. After 1995, the urbanrural difference in $\mathrm{CF}$ and $E_{a}$ turned to a decreasing trend and that for CA became stable due to the decline of $\mathrm{CF}$ offsetting the increase of aerosols loading. Compared to Fig. 2a, the urban-rural difference in temperatures shared a similar interannual variability with that in CA, and the significant correlation between them further proved it (see Fig. 4). Based on their robust relationship, it was likely that the hiatus of urbanizationinduced warming in East China was caused by the drop of the urban-rural difference in CA after 1995.

To prove this hypothesis, we quantified the effect of changes in CA on the temperatures based on the radiative energy balance on land surface. The results show that the urbanization-induced changes in CA have the largest effect on $L_{d}$ and $R_{s}$, which explains most of the trend of urban-rural difference for $R_{S}(63.0 \%)$ and that for $L_{d}(55.6 \%)$ during 1960-2014 in East China (Fig. 3c). After adjusting the effect from changes in surface radiative balance, the trend of urban-rural difference for $T_{\text {mean }}$ almost disappears (see Fig. 7). Importantly, the difference among stages in urbanization-induced warming for temperatures almost disappears as well (see Fig. 8b).

Another problem worth discussing is why the urbanrural difference of cloud cover tends to decrease after 1995. As shown in Fig. 3, after 1995, the relative humidity and vapor pressure decreased significantly with urbanization in East China, which is consistent with the "urban dry island" mentioned by existing studies (Cuadrat et al. 2015; Hage 1975; Unkašević et al. 2001). First, the decrease in water vapor pressure not only led to the increased mixing of water vapor in the boundary layer and therefore the decreased availability of convective potential energy but also reduced the transportation of moisture from the surface to the upper troposphere (Zhang et al. 2009). Second, the impact of aerosol emissions on changes in cloud cover is uncertain (Ghan et al. 2016). The urban-rural difference in CF remained stable until 1995 and then began to decrease in East China, thus offsetting the increase in aerosols with urbanization and resulting in no significant trend in CA after 1995 (see Fig. 3a). After 2004, the urbanization caused the obvious urban dry island in West China, implying that the urban dry island would occur after the city grew to a certain scale.

Furthermore, why does urbanization cause a significant urban dry island effect? One main reason is the land-cover change associated with urbanization (Chen et al. 2014). With urban expansion, a large amount of vegetation and water is transformed into the impervious surface such as roads and buildings, which leads to a less evapotranspiration and more surface absorbed radiation partitioned into sensible rather than latent heat (Peng et al. 2016; Xu and Liu 2015). Consequently, the moisture of urban atmosphere will decrease due to less water vapor imported from land surface (Danielaini et al. 2017).

Besides, the land-cover change caused by urbanization will change the land surface energy balance, thus affecting the urban heat island effect. During daytime, the high-rise urban buildings store solar radiation and have a shading effect for land surface, which can suppress the urban heat island effect (Loughner et al. 2012). After sunset, the buildings will release the stored energy and trap the longwave radiation emitted from surface, which can amplify the urban heat island effect at night (Kuang et al. 2015). Therefore, it may explain the residual urbanization-caused cooling effect on $T_{\max }$ and urbanization-caused warming effect on $T_{\min }$ after adjusting the effect of radiation fluxes over East China (see Fig. 7c). Additionally, the increase in urban density and height will reduce the wind speed and thus weaken the diffusion of urban air pollution, which may be an important cause for the increase of aerosol loading with urbanization (Guo et al. 2011; McVicar et al. 2008). In general, with denser buildings and worse air pollution, the urbanization tends to reduce the surface solar radiation and increase the energy stored in compact structures during daytime, whereas reduces the longwave radiative cooling efficiency and releases energy stored in buildings during nighttime. Therefore, the urbanizationinduced warming of $T_{\max }$ in East China is lower than that in West China, whereas the opposite is true for $T_{\min }$ (see Figs. 2a and 2b).

In the future, it is worth noting whether the urbanization would continue to intensify the urban dry island effect and further reduce the CA. With the further expansion of urban scale come an increase of urban impervious surface and a reduction of wetland and vegetation, which tend to intensify the urban dry island effect and reduce urban cloud cover. Beside cloud cover, the variability of CA also depends on the change in the aerosols loading. With more attention to air quality, there have been many emission-cutting measures implemented in cities over China, such as the promotion of new energy vehicles and the limitation of coal consumption, which would suppress and even reduce the aerosols emission in urban areas. In general, the urban-rural difference in CA is more likely to decrease with the optimization of urban energy structure, which may effectively further inhibit the urbanization-caused warming over China.

\section{Conclusions}

This paper was based on observations obtained from 2400 weather stations in China that were used to 
construct a homogenized urban-rural reference series. Based on the comparison between urban and rural areas, we analyzed the effects of urbanization on the warming trends of daily temperatures. Further, we explored how radiative forcing changes with urbanization and therefore affects the warming trends of observed temperatures.

From 1960 to 2014, the warming trends of temperatures exhibited significant urban-rural differences over China. Urbanization leads to increases in the warming rates of $T_{\max }, T_{\min }$, and $T_{\text {mean }}$ of $0.025^{\circ}, 0.095^{\circ}$, and $0.058^{\circ} \mathrm{C}(10 \mathrm{yr})^{-1}$, which represent $11.4 \%, 26.7 \%$, and $22.3 \%$ of the overall warming, respectively.

Meanwhile, the urban-rural difference in $R_{s}\left(L_{d}\right)$ increased by $0.471 \pm 0.055 \mathrm{~W} \mathrm{~m}^{-2}(10 \mathrm{yr})^{-1}\left[0.536 \mathrm{~W} \mathrm{~m}^{-2}\right.$ $(10 \mathrm{yr})^{-1}$ ], accounting for $44.3 \%(31.7 \%)$ of the overall trend over China during 1960-2014. Of the three driving factors of $R_{s}\left(L_{d}\right)$, aerosols are the most important components, as they explain $74.1 \%(54.9 \%)$ of the decrease (increase) in $R_{s}\left(L_{d}\right)$. This is followed by the feedback of $T_{a}$, which contributes $29.5 \%$ of $L_{d}$ but has no significant effect on $R_{s}$; finally, the contributions of $E_{a}$ and their interaction effects are negligible, as they only account for $-2.2 \%$ to $10.4 \%$ of the overall effects on $L_{d}$.

According to the attribution diagnostics, the urbanization-induced increase in $L_{d}$ with urbanization led to urban warming of $0.082^{\circ}, 0.102^{\circ}$, and $0.093^{\circ} \mathrm{C}$ $(10 \mathrm{yr})^{-1}$ for $T_{\max }, T_{\min }$, and $T_{\text {mean }}$, respectively, while the urbanization-induced decrease in $R_{S}$ caused urban cooling of $-0.044^{\circ},-0.026^{\circ}$, and $-0.037^{\circ} \mathrm{C}(10 \mathrm{yr})^{-1}$ for $T_{\max }, T_{\min }$, and $T_{\text {mean }}$ respectively. These values contributed changes of $0.037^{\circ} \mathrm{C}(10 \mathrm{yr})^{-1}(151.5 \%), 0.074^{\circ} \mathrm{C}$ $(10 \mathrm{yr})^{-1}(78.2 \%)$, and $0.056^{\circ} \mathrm{C}(10 \mathrm{yr})^{-1}(96.6 \%)$ due to the radiative forcing caused by urbanization.

Overall, after adjusting the impacts of $R_{s}$ and $L_{d}$, the urbanization warming effect of air temperatures in West China almost disappeared, while the observed urban cooling of $T_{\max }\left[-0.030^{\circ} \pm 0.005^{\circ} \mathrm{C}(10 \mathrm{yr})^{-1}\right]$ and urban warming of $T_{\min }\left[0.039^{\circ} \pm 0.004^{\circ} \mathrm{C}(10 \mathrm{yr})^{-1}\right]$ remained in East China, which may be caused by the high density of buildings and anthropogenic heat release in urban areas in East China. The difference in the trend of urban warming effect before and after 1980 decreased by $62.3 \%$ in East China and $75.5 \%$ for $T_{\text {mean }}$ in West China. Additionally, the difference in the trend of urban warming effect before and after 1995 decreased by 98.1\% in East China, which indicated that the decrease in cloud cover caused by urban drying was the main driving factor of the slowdown of urban warming after 1995 in East China.

These results still have some uncertainties that require further study. For instance, the selection criteria of the reference stations were compromised for various reasons, and the observations obtained at reference stations may retain some residual effects from nearby changes in land use/land cover (Ren et al. 2015). Additionally, the empirical models used to derive $L_{d}$ still have some shortcomings (Wang and Dickinson 2013a). For instance, the changes in CF do not fully reflect the effects of cloud changes on longwave radiation, and the radiative energy balance on the surface is sensitive to other cloud characteristics, such as the cloud height and thickness (Jakob et al. 2005; Stephens et al. 2012; Trenberth et al. 2009), which have been found to have changed with urbanization in previous studies (Cheng and Nnadi 2014; Williams et al. 2015). Given the lack of observation of $L_{d}$, the feedback of $T_{a}$ on $L_{d}$ may cause a certain uncertainty to our results derived from empirical models.

However, this paper draws attention to exploring the underlying mechanism of urbanization effects and systematically understanding the complex processes that they involve; it thus provides a basis for the quantitative estimation of urbanization effects on global or regional warming trends.

Acknowledgments. This study was funded by the National Basic Research Program of China (2017YFA0603601 and 2018YFC1507701), Key Project of National Natural Science Foundation of China (51639001), China Postdoctoral Science Foundation (2018M641248), Postdoctoral Innovation Talent Program (212643), and the National Natural Science Foundation of China (41525018 and 41505134). The latest observational data were obtained from the CMA (http://www.cma.gov.cn).

\section{REFERENCES}

Ackerman, B., 1987: Climatology of Chicago area urbanrural differences in humidity. J. Climate Appl. Meteor., 26, 427-430, https://doi.org/10.1175/1520-0450(1987)026<0427: COCAUR $>2.0 . \mathrm{CO} ; 2$.

Ångström, A. K., 1915: A study of the radiation of the atmosphere: Based upon observations of the nocturnal radiation during expeditions to Algeria and to California. Smithsonian Institution Miscellaneous Collections, Vol. 65, 159 pp.

_ 1924: Solar and terrestrial radiation. Report to the international commission for solar research on actinometric investigations of solar and atmospheric radiation. Quart. J. Roy. Meteor. Soc., 50, 121-126, https://doi.org/10.1002/ qj. 49705021008 .

Bilbao, J., and A. H. de Miguel, 2007: Estimation of daylight downward longwave atmospheric irradiance under clear-sky and all-sky conditions. J. Appl. Meteor. Climatol., 46, 878-889, https://doi.org/10.1175/JAM2503.1.

Boudjellal, L., and F. Bourbia, 2018: An evaluation of the cooling effect efficiency of the oasis structure in a Saharan town through remotely sensed data. Int. J. Environ. Stud., 75, 309320, https://doi.org/10.1080/00207233.2017.1361610. 
Brunt, D., 1932: Notes on radiation in the atmosphere. I. Quart. J. Roy. Meteor. Soc., 58, 389-420, https://doi.org/10.1002/ qj. 49705824704 .

Brutsaert, W., 1975: On a derivable formula for long-wave radiation from clear skies. Water Resour. Res., 11, 742-744, https:// doi.org/10.1029/WR011i005p00742.

Cao, C., X. Lee, S. Liu, N. Schultz, W. Xiao, M. Zhang, and L. Zhao, 2016: Urban heat islands in China enhanced by haze pollution. Nat. Commun., 7, 12509, https://doi.org/10.1038/ ncomms 12509.

Cayan, D. R., and A. V. Douglas, 1984: Urban influences on surface temperatures in the southwestern United States during recent decades. J. Climate Appl. Meteor., 23, 1520-1530, https:// doi.org/10.1175/1520-0450(1984)023<1520:UIOSTI>2.0.CO;2.

Chen, A., L. Yao, R. Sun, and L. Chen, 2014: How many metrics are required to identify the effects of the landscape pattern on land surface temperature? Ecol. Indic., 45, 424-433, https:// doi.org/10.1016/j.ecolind.2014.05.002.

Cheng, C. H., and F. Nnadi, 2014: Predicting downward longwave radiation for various land use in all-sky condition: Northeast Florida. Adv. Meteor., 2014, 525148, http://dx.doi.org/10.1155/ 2014/525148

China State Statistical Bureau, 1994: China Statistical Yearbook 2014. National Bureau of Statistics of China, http:// data.stats.gov.cn/english/publish.htm? sort $=1$.

Choi, M., J. M. Jacobs, and W. P. Kustas, 2008: Assessment of clear and cloudy sky parameterizations for daily downwelling longwave radiation over different land surfaces in Florida, USA. Geophys. Res. Lett., 35, L20402, https://doi.org/10.1029/ 2008GL035731.

Chrysanthou, A., G. van der Schrier, E. van den Besselaar, A. Klein Tank, and T. Brandsma, 2014: The effects of urbanization on the rise of the European temperature since 1960. Geophys. Res. Lett., 41, 7716-7722, https://doi.org/10.1002/ 2014 GL061154.

Crawford, T. M., and C. E. Duchon, 1999: An improved parameterization for estimating effective atmospheric emissivity for use in calculating daytime downwelling longwave radiation. J. Appl. Meteor., 38, 474-480, https://doi.org/10.1175/15200450(1999)038<0474:AIPFEE > 2.0.CO;2.

Cuadrat, J. M., S. Vicente-Serrano, and M. A. Saz, 2015: Influence of different factors on relative air humidity in Zaragoza, Spain. Front Earth Sci, 3, 10, https://doi.org/10.3389/feart.2015.00010.

Danielaini, T. T., B. Maheshwari, and D. Hagare, 2017: Defining rural-urban interfaces for understanding ecohydrological processes in West Java, Indonesia: Part II. Its application to quantify rural-urban interface ecohydrology. Ecohydrol. Hydrobiol., 18, 37-51, https://doi.org/10.1016/j.ecohyd.2017.11.007.

Du, J., K. Wang, J. Wang, S. Jiang, and C. Zhou, 2018: Diurnal cycle of surface air temperature within China in current reanalyses: Evaluation and diagnostics. J. Climate, 31, 45854603, https://doi.org/10.1175/JCLI-D-17-0773.1.

Duarte, H. F., N. L. Dias, and S. R. Maggiotto, 2006: Assessing daytime downward longwave radiation estimates for clear and cloudy skies in Southern Brazil. Agric. For. Meteor., 139, 171181, https://doi.org/10.1016/j.agrformet.2006.06.008.

Dufresne, J.-L., C. Gautier, P. Ricchiazzi, and Y. Fouquart, 2002: Longwave scattering effects of mineral aerosols. J. Atmos. Sci., 59, 1959-1966, https://doi.org/10.1175/1520-0469(2002)059<1959: LSEOMA $>2.0 . \mathrm{CO} ; 2$

Eastman, R., and S. G. Warren, 2013: A 39-yr survey of cloud changes from land stations worldwide 1971-2009: Long-term trends, relation to aerosols, and expansion of the tropical belt.
J. Climate, 26, 1286-1303, https://doi.org/10.1175/JCLI-D-1200280.1 .

Fujibe, F., 2011: Urban warming in Japanese cities and its relation to climate change monitoring. Int. J. Climatol., 31, 162-173, https://doi.org/10.1002/joc.2142.

Gaffin, S. R., and Coauthors, 2008: Variations in New York City's urban heat island strength over time and space. Theor. Appl. Climatol., 94, 1-11, https://doi.org/10.1007/s00704-007-0368-3.

Gallo, K. P., T. W. Owen, D. R. Easterling, and P. F. Jamason, 1999: Temperature trends of the U.S. Historical Climatology Network based on satellite-designated land use/land cover. J. Climate, 12, 1344-1348, https://doi.org/10.1175/15200442(1999)012<1344:TTOTUS>2.0.CO;2.

Ghan, S., and Coauthors, 2016: Challenges in constraining anthropogenic aerosol effects on cloud radiative forcing using present-day spatiotemporal variability. Proc. Natl. Acad. Sci. USA, 113, 5804-5811, https://doi.org/10.1073/pnas.1514036113.

Guo, H., M. Xu, and Q. Hu, 2011: Changes in near-surface wind speed in China: 1969-2005. Int. J. Climatol., 31, 349-358, https://doi.org/10.1002/joc.2091.

Hage, K. D., 1975: Urban-rural humidity differences. J. Appl. Meteor., 14, 1277-1283, https://doi.org/10.1175/1520-0450(1975) 014<1277:URHD>2.0.CO;2.

Hansen, J., R. Ruedy, M. Sato, M. Imhoff, W. Lawrence, D. Easterling, T. Peterson, and T. Karl, 2001: A closer look at United States and global surface temperature change. J. Geophys. Res., 106, 23 947-23 963, https://doi.org/10.1029/ 2001JD000354.

Hao, L., X. Huang, M. Qin, Y. Liu, W. Li, and G. Sun, 2018: Ecohydrological processes explain urban dry island effects in a wet region, southern China. Water Resour. Res., 54, 67576771, https://doi.org/10.1029/2018WR023002.

He, Y., G. Jia, Y. Hu, and Z. Zhou, 2013: Detecting urban warming signals in climate records. Adv. Atmos. Sci., 30, 1143-1153, https://doi.org/10.1007/s00376-012-2135-3.

_, K. Wang, C. Zhou, and M. Wild, 2018: A revisit of global dimming and brightening based on the sunshine duration. Geophys. Res. Lett., 45, 4281-4289, https://doi.org/10.1029/ 2018 GL077424.

Henry, J. A., S. E. Dicks, and G. A. Marotz, 1985: Urban and rural humidity distributions: Relationships to surface materials and land use. J. Climatol., 5, 53-62, https://doi.org/10.1002/ joc.3370050105.

Iacono, M. J., J. S. Delamere, E. J. Mlawer, M. W. Shephard, S. A. Clough, and W. D. Collins, 2008: Radiative forcing by longlived greenhouse gases: Calculations with the AER radiative transfer models. J. Geophys. Res., 113, D13103, https://doi.org/ 10.1029/2008JD009944.

Idso, S. B., and R. D. Jackson, 1969: Thermal radiation from the atmosphere. J. Geophys. Res., 74, 5397-5403, https://doi.org/ 10.1029/JC074i023p05397.

Inoue, T., and F. Kimura, 2004: Urban effects on low-level clouds around the Tokyo metropolitan area on clear summer days. Geophys. Res. Lett., 31, L05103, https://doi.org/10.1029/ 2003 GL018908.

Jakob, C., G. Tselioudis, and T. Hume, 2005: The radiative, cloud, and thermodynamic properties of the major tropical western Pacific cloud regimes. J. Climate, 18, 1203-1215, https:// doi.org/10.1175/JCLI3326.1.

Jones, P. D., P. Ya. Groisman, M. Coughlan, N. Plummer, W. C. Wang, and T. R. Karl, 1990: Assessment of urbanization effects in time series of surface air temperature over land. Nature, 347, 169-172, https://doi.org/10.1038/347169a0. 
— D. H. Lister, and Q. Li, 2008: Urbanization effects in largescale temperature records, with an emphasis on China. J. Geophys. Res., 113, D16122, https://doi.org/10.1029/ 2008JD009916.

Kai, K., M. Matsuda, and R. Sato, 1997: Oasis effect observed at Zhangye oasis in the Hexi corridor, China. J. Meteor. Soc. Japan, 75, 1171-1178, https://doi.org/10.2151/jmsj1965.75.6_ 1171

Kalnay, E., and M. Cai, 2003: Impact of urbanization and land-use change on climate. Nature, 423, 528-531, https://doi.org/ 10.1038/nature01675.

Karl, T. R., H. F. Diaz, and G. Kukla, 1988: Urbanization: Its detection and effect in the United States climate record. J. Climate, 1, 1099-1123, https://doi.org/10.1175/1520-0442(1988)001<1099: UIDAEI $>2.0 . \mathrm{CO} ; 2$.

Kato, S., and Y. Yamaguchi, 2007: Estimation of storage heat flux in an urban area using ASTER data. Remote Sens. Environ., 110, 1-17, https://doi.org/10.1016/j.rse.2007.02.011.

Kjaersgaard, J. H., F. Plauborg, and S. Hansen, 2007: Comparison of models for calculating daytime long-wave irradiance using long term data set. Agric. For. Meteor., 143, 49-63, https:// doi.org/10.1016/j.agrformet.2006.11.007.

Kuang, W., and Coauthors, 2015: Quantifying the heat flux regulation of metropolitan land use/land cover components by coupling remote sensing modeling with in situ measurement J. Geophys. Res. Atmos., 120,113-130, https://doi.org/10.1002/ 2014JD022249.

Lokoshchenko, M. A., 2017: Urban heat island and urban dry island in Moscow and their centennial changes. J. Appl. Meteor. Climatol., 56, 2729-2745, https://doi.org/10.1175/JAMC-D-16 0383.1.

Loughner, C. P., D. J. Allen, D.-L. Zhang, K. E. Pickering, R. R. Dickerson, and L. Landry, 2012: Roles of urban tree canopy and buildings in urban heat island effects: Parameterization and preliminary results. J. Appl. Meteor. Climatol., 51, 17751793, https://doi.org/10.1175/JAMC-D-11-0228.1.

Ma, Q., K. Wang, and M. Wild, 2014: Evaluations of atmospheric downward longwave radiation from 44 coupled general circulation models of CMIP5. J. Geophys. Res. Atmos., 119, 4486-4497, https://doi.org/10.1002/2013JD021427.

,-- , and -2015 : Impact of geolocations of validation data on the evaluation of surface incident shortwave radiation from Earth system models. J. Geophys. Res. Atmos., 120, 6825-6844, https://doi.org/10.1002/2014JD022572.

Magee, N. B., E. Melaas, P. M. Finocchio, M. Jardel, A. Noonan, and M. J. Iacono, 2014: Blue Hill Observatory sunshine: Assessment of climate signals in the longest continuous meteorological record in North America. Bull. Amer. Meteor. Soc. 95, 1741-1751, https://doi.org/10.1175/BAMS-D-12-00206.1.

Markowicz, K. M., P. J. Flatau, A. M. Vogelmann, P. K. Quinn, and E. J. Welton, 2003: Clear-sky infrared aerosol radiative forcing at the surface and the top of the atmosphere. Quart. J. Roy. Meteor. Soc., 129, 2927-2947, https://doi.org/10.1256/qj.02.224.

McNider, R. T., and Coauthors, 2012: Response and sensitivity of the nocturnal boundary layer over land to added longwave radiative forcing. J. Geophys. Res., 117, D14106, https:// doi.org/10.1029/2012JD017578.

McVicar, T. R., T. G. Van Niel, L. T. Li, M. L. Roderick, D. P. Rayner, L. Ricciardulli, and R. J. Donohue, 2008: Wind speed climatology and trends for Australia, 1975-2006: Capturing the stilling phenomenon and comparison with near-surface reanalysis output. Geophys. Res. Lett., 35, L20403, https:// doi.org/10.1029/2008GL035627.
Moriwaki, R., K. Watanawe, and K. Morimoto, 2013: Urban dry island phenomenon and its impact on cloud base level. J. Japan Soc. Civil Eng., 1, 521-529, http://dx.doi.org/10.2208/ journalofjsce.1.1_521.

Norris, J. R., and M. Wild, 2009: Trends in aerosol radiative effects over China and Japan inferred from observed cloud cover, solar "dimming," and solar "brightening". J. Geophys. Res., 114, D00D15, https://doi.org/10.1029/2008JD011378.

Oke, T. R., 1982: The energetic basis of the urban heat island. Quart. J. Roy. Meteor. Soc., 108,1-24, https://doi.org/10.1002/ qj. 49710845502 .

Owen, T., 1998: Using DMSP-OLS light frequency data to categorize urban environments associated with US climate observing stations. Int. J. Remote Sens., 19, 3451-3456, https:// doi.org/10.1080/014311698214127.

Panicker, A., G. Pandithurai, P. Safai, and S. Kewat, 2008: Observations of enhanced aerosol longwave radiative forcing over an urban environment. Geophys. Res. Lett., 35, L04817, https://doi.org/10.1029/2007GL032879.

Peng, J., P. Xie, Y. Liu, and J. Ma, 2016: Urban thermal environment dynamics and associated landscape pattern factors: A case study in the Beijing metropolitan region. Remote Sens. Environ., 173, 145-155, https://doi.org/10.1016/j.rse.2015.11.027.

Peterson, T. C., 2003: Assessment of urban versus rural in situ surface temperatures in the contiguous United States: No difference found. J. Climate, 16, 2941-2959, https://doi.org/ 10.1175/1520-0442(2003)016<2941:AOUVRI > 2.0.CO;2.

Portman, D. A., 1993: Identifying and correcting urban bias in regional time series: Surface temperature in China's northern plains. J. Climate, 6, 2298-2308, https://doi.org/10.1175/15200442(1993)006<2298:IACUBI >2.0.CO;2.

Prata, A., 1996: A new long-wave formula for estimating downward clear-sky radiation at the surface. Quart. J. Roy. Meteor. Soc., 122, 1127-1151, https://doi.org/10.1002/qj.49712253306.

Ren, G., and Y. Zhou, 2014: Urbanization effect on trends of extreme temperature indices of national stations over mainland China, 1961-2008. J. Climate, 27, 2340-2360, https://doi.org/ 10.1175/JCLI-D-13-00393.1.

— Z. Chu, Z. Chen, and Y. Ren, 2007: Implications of temporal change in urban heat island intensity observed at Beijing and Wuhan stations. Geophys. Res. Lett., 34, L05711, https:// doi.org/10.1029/2006GL027927.

- Y. Zhou, Z. Chu, J. Zhou, A. Zhang, J. Guo, and X. Liu, 2008: Urbanization effects on observed surface air temperature trends in North China. J. Climate, 21, 1333-1348, https:// doi.org/10.1175/2007JCLI1348.1.

, A. Zhang, Z. Chu, J. Zhou, Y. Ren, and Y. Zhou, 2010: Principles and procedures for selecting reference surface air temperature stations in China. Meteor. Sci. Technol., 38, 78-85. and Coauthors, 2015: An integrated procedure to determine a reference station network for evaluating and adjusting urban bias in surface air temperature data. J. Appl. Meteor. Climatol., 54, 1248-1266, https://doi.org/10.1175/ JAMC-D-14-0295.1.

Ren, Y., and G. Ren, 2011: A remote-sensing method of selecting reference stations for evaluating urbanization effect on surface air temperature trends. J. Climate, 24, 3179-3189, https:// doi.org/10.1175/2010JCLI3658.1

Romanov, P., 1999: Urban influence on cloud cover estimated from satellite data. Atmos. Environ., 33, 4163-4172, https://doi.org/ 10.1016/S1352-2310(99)00159-4.

Sanchez-Lorenzo, A., J. Calbo, M. Brunetti, and C. Deser, 2009: Dimming/brightening over the Iberian Peninsula: Trends in 
sunshine duration and cloud cover and their relations with atmospheric circulation. J. Geophys. Res., 114, D00D09, https://doi.org/10.1029/2008JD011394.

Sanchez-Romero, A., A. Sanchez-Lorenzo, J. Calbó, J. González, and C. Azorin-Molina, 2014: The signal of aerosol-induced changes in sunshine duration records: A review of the evidence. J. Geophys. Res. Atmos., 119, 4657-4673, https:// doi.org/10.1002/2013JD021393.

Schneider, A., M. A. Friedl, and D. Potere, 2009: A new map of global urban extent from MODIS satellite data. Environ. Res. Lett., 4, 044003, https://doi.org/10.1088/1748-9326/4/4/044003.

Schwartz, S. E., 1996: The whitehouse effect-Shortwave radiative forcing of climate by anthropogenic aerosols: An overview. J. Aerosol Sci., 27, 359-382, https://doi.org/10.1016/00218502(95)00533-1.

Stephens, G. L., and T. J. Greenwald, 1991: The Earth's radiation budget and its relation to atmospheric hydrology: 2. Observations of cloud effects. J. Geophys. Res., 96, 15 325-15340, https://doi.org/10.1029/91JD00972.

—, M. Wild, P. W. Stackhouse, T. L'Ecuyer, S. Kato, and D. S. Henderson, 2012: The global character of the flux of downward longwave radiation. J. Climate, 25, 2329-2340, https:// doi.org/10.1175/JCLI-D-11-00262.1.

Sun, Y., X. B. Zhang, G. Y. Ren, F. W. Zwiers, and T. Hu, 2016: Contribution of urbanization to warming in China. Nat. Climate Change, 6, 706-709, https://doi.org/10.1038/nclimate2956.

Tang, W.-J., K. Yang, J. Qin, C. Cheng, and J. He, 2011: Solar radiation trend across China in recent decades: A revisit with quality-controlled data. Atmos. Chem. Phys., 11, 393-406, https://doi.org/10.5194/acp-11-393-2011.

Trenberth, K. E., J. T. Fasullo, and J. Kiehl, 2009: Earth's global energy budget. Bull. Amer. Meteor. Soc., 90, 311-323, https:// doi.org/10.1175/2008BAMS2634.1.

Unkašević, M., O. Jovanović, and T. Popović, 2001: Urbansuburban/rural vapour pressure and relative humidity differences at fixed hours over the area of Belgrade city. Theor. Appl. Climatol., 68, 67-73, https://doi.org/10.1007/s007040170054.

Wang, F., and Q. Ge, 2012: Estimation of urbanization bias in observed surface temperature change in China from 1980 to 2009 using satellite land-use data. Chin. Sci. Bull., 57, 17081715, https://doi.org/10.1007/s11434-012-4999-0.

Wang, J., J. Feng, Z. Yan, Y. Hu, and G. Jia, 2012: Nested highresolution modeling of the impact of urbanization on regional climate in three vast urban agglomerations in China. J. Geophys. Res., 117, D21103, https://doi.org/10.1029/ 2012JD018226.

— S. Tett, and Z. Yan, 2017: Correcting urban bias in large-scale temperature records in China, 1980-2009. Geophys. Res. Lett., 44, 401-408, https://doi.org/10.1002/2016GL071524.

Wang, K., 2014: Measurement biases explain discrepancies between the observed and simulated decadal variability of surface incident solar radiation. Sci. Rep., 4, 6144, https://doi.org/ 10.1038/srep06144.

- and S. Liang, 2009: Global atmospheric downward longwave radiation over land surface under all-sky conditions from 1973 to 2008. J. Geophys. Res., 114, D19101, https://doi.org/10.1029/ 2009JD011800.

, and R. E. Dickinson, 2013: Global atmospheric downward longwave radiation at the surface from ground-based observations, satellite retrievals, and reanalyses. Rev. Geophys., 51, 150-185, https://doi.org/10.1002/rog.20009.

—, R. Dickinson, M. Wild, and S. Liang, 2012: Atmospheric impacts on climatic variability of surface incident solar radiation. Atmos. Chem. Phys., 12, 9581-9592, https://doi.org/ 10.5194/acp-12-9581-2012.

_ , Q. Ma, Z. J. Li, and J. K. Wang, 2015: Decadal variability of surface incident solar radiation over China: Observations, satellite retrievals, and reanalyses. J. Geophys. Res., 120, 6500 6514, https://doi.org/10.1002/2015JD023420.

—, S. Jiang, J. Wang, C. Zhou, X. Wang, and X. Lee, 2017: Comparing the diurnal and seasonal variabilities of atmospheric and surface urban heat islands based on the Beijing urban meteorological network. J. Geophys. Res., 122, 21312154, https://doi.org/10.1002/2016JD025304.

Wang, X. L., H. Chen, Y. Wu, Y. Feng, and Q. Pu, 2010: New techniques for the detection and adjustment of shifts in daily precipitation data series. J. Appl. Meteor. Climatol., 49, 24162436, https://doi.org/10.1175/2010JAMC2376.1.

Wang, Y., Y. Yang, N. Zhao, C. Liu, and Q. Wang, 2012: The magnitude of the effect of air pollution on sunshine hours in China. J. Geophys. Res., 117, D00V14, https://doi.org/10.1029/ 2011JD016753.

,,-- S. Han, Q. Wang, and J. Zhang, 2013: Sunshine dimming and brightening in Chinese cities (1955-2011) was driven by air pollution rather than clouds. Climate Res., 56, 11-20, https://doi.org/10.3354/cr01139.

—, M. Wild, A. Sanchez-Lorenzo, and V. Manara, 2017: Urbanization effect on trends in sunshine duration in China. Ann. Geophys., 35, 839-851, https://doi.org/10.5194/angeo-35-839-2017.

Warren, S. G., R. M. Eastman, and C. J. Hahn, 2007: A survey of changes in cloud cover and cloud types over land from surface observations, 1971-96. J. Climate, 20, 717-738, https://doi.org/ 10.1175/JCLI4031.1.

Wild, M., 2016: Decadal changes in radiative fluxes at land and ocean surfaces and their relevance for global warming. Wiley Interdiscip. Rev.: Climate Change, 7, 91-107, https://doi.org/10.1002/wcc.372.

Williams, A. P., and Coauthors, 2015: Urbanization causes increased cloud base height and decreased fog in coastal Southern California. Geophys. Res. Lett., 42, 1527-1536, https://doi.org/10.1002/2015GL063266.

Xie, Y., Y. Jiang, and E. Greenman, 2008: Did send-down experience benefit youth? A reevaluation of the social consequences of forced urban-rural migration during China's Cultural Revolution. Soc. Sci. Res., 37, 686-700, https:// doi.org/10.1016/j.ssresearch.2007.08.002.

Xu, W., Q. Li, X. L. Wang, S. Yang, L. Cao, and Y. Feng, 2013: Homogenization of Chinese daily surface air temperatures and analysis of trends in the extreme temperature indices. J. Geophys. Res. Atmos., 118, 9708-9720, https://doi.org/10.1002/jgrd.50791.

$\mathrm{Xu}, \mathrm{Y}$., and Y. Liu, 2015: Monitoring the near-surface urban heat island in Beijing, China by satellite remote sensing. Geogr. Res., 53, 16-25, https://doi.org/10.1111/1745-5871.12092.

Yang, K., T. Koike, and B. Ye, 2006: Improving estimation of hourly, daily, and monthly solar radiation by importing global data sets. Agric. For. Meteor., 137, 43-55, https://doi.org/ 10.1016/j.agrformet.2006.02.001.

Yang, P., G. Ren, and W. Hou, 2017: Temporal-spatial patterns of relative humidity and the urban dryness island effect in Beijing City. J. Appl. Meteor. Climatol., 56, 2221-2237, https://doi.org/ 10.1175/JAMC-D-16-0338.1.

Yang, X., Y. Hou, and B. Chen, 2011: Observed surface warming induced by urbanization in east China. J. Geophys. Res., 116, D14113, https://doi.org/10.1029/2010JD015452.

Zhang, A. Y., G. Y. Ren, J. X. Zhou, Z. Y. Chu, Y. Y. Ren, and G. L. Tang, 2010: Urbanization effect on surface air temperature trends over China. Acta Meteor. Sin., 68, 957-966. 
Zhang, C. L., F. Chen, S. G. Miao, Q. C. Li, X. A. Xia, and C. Y. Xuan, 2009: Impacts of urban expansion and future green planting on summer precipitation in the Beijing metropolitan area. J. Geophys. Res., 114, D02116, https://doi.org/10.1029/ 2008JD010328.

Zheng, X., W. Kang, T. Zhao, Y. Luo, C. Duan, and J. Chen, 2008: Long-term trends in sunshine duration over YunnanGuizhou Plateau in Southwest China for 1961-2005. Geophys. Res. Lett., 35, L15707, https://doi.org/10.1029/ 2008 GL034482.
Zhou, L. M., R. E. Dickinson, Y. Tian, J. Fang, Q. Li, R. K. Kaufmann, C. J. Tucker, and R. B. Myneni, 2004: Evidence for a significant urbanization effect on climate in China. Proc. Natl. Acad. Sci. USA, 101, 9540-9544, https://doi.org/10.1073/ pnas.0400357101.

Zhou, W., G. Huang, and M. L. Cadenasso, 2011: Does spatial configuration matter? Understanding the effects of land cover pattern on land surface temperature in urban landscapes. Landsc. Urban Plann., 102, 54-63, https://doi.org/10.1016/ j.landurbplan.2011.03.009. 